INVITED PAPER

\author{
Sören Stenlund \\ soren.stenlund@filosofi.uu.se
}

\title{
On the Origin of Symbolic Mathematics and Its Significance for Wittgenstein's Thought ${ }^{1}$
}

\section{Abstract}

The main topic of this essay is symbolic mathematics or the method of symbolic construction, which I trace to the end of the sixteenth century when Franciscus Vieta invented the algebraic symbolism and started to use the word 'symbolic' in the relevant, non-ontological sense. This approach has played an important role for many of the great inventions in modern mathematics such as the introduction of the decimal place-value system of numeration, Descartes' analytic geometry, and Leibniz's infinitesimal calculus. It was also central for the rigorization movement in mathematics in the late nineteenth century, as well as for the mathematics of modern physics in the 20th century.

However, the nature of symbolic mathematics has been concealed and confused due to the strong influence of the heritage from the Euclidean and Aristotelian traditions. This essay sheds some light on

\footnotetext{
${ }^{1}$ I am indebted to Aki Kanamori, Pär Segerdahl, Kim Solin and Anders Öberg for helpful comments on an earlier version of this essay. Special thanks to Pär Segerdahl who helped me improve the final version of the book on which this article is based. The book is entitled The Origin of Symbolic Mathematics and the End of the Science of Quantity, Uppsala Department of Philosophy 2014, and is available at: < bttp:/ / urn.kb.se/ resolve?urn $=$ urn \% 3 Anbn\%3 Ase \%3 Aun\%3 Adiva-221570>
} 
what has been concealed by approaching some of the crucial issues from a historical perspective.

Furthermore, I argue that the conception of modern mathematics as symbolic mathematics was essential to Wittgenstein's approach to the foundations and nature of mathematics. This connection between Wittgenstein's thought and symbolic mathematics provides the resources for countering the still prevalent view that he defended an uttrely idiosyncratic conception, disconnected from the progress of serious science. Instead, his project can be seen as clarifying ideas that have been crucial to the development of mathematics since early modernity.

\section{History and heritage}

The rise of symbolic mathematics in the seventeenth century was not just a more or less continuous course of development, or an extension, of ancient Greek and medieval mathematical thought. As the philosopher Jacob Klein has argued, it was a transformation, connected with the extensive cultural change that took place in the beginning of modern times. Many essential features of Greek mathematical thought came to an end through this transformation and therefore no longer belong to our mathematical heritage. New forms of mathematical thought were created through the transformation, especially due to the increased use of algebraic symbolism.

The normal interest in the history of mathematics (among mathematicians who write history of mathematics) is an interest in our mathematical heritage. This interest therefore tends to be conditioned by the contemporary situation and is not always an interest in what actually bappened in mathematics of the past regardless of the contemporary situation. Only history in the latter sense deserves to be called history. ${ }^{2}$ But history and heritage are often confused and one consequence of this kind of confusion is that the transformation of mathematics at the beginning of modern times is concealed. Features of modern mathematics are projected upon mathematics of the past, and the deep contrasts between ancient and modern mathematics are concealed. As a consequence,

2 On the difference between history and heritage, see Grattan-Guinness (2004). 
the nature of modern mathematics as symbolic mathematics is not understood as the new beginning of mathematics that it was.

By taking a closer look at some examples from the history of mathematics it will be argued that what actually happened in mathematics in the past supports the view that the essence of modern mathematics is symbolic mathematics.

\section{Are there proofs by mathematical induction in Euclid's Elements?}

There is quite strong disagreement among historians of mathematics about the origin of proof by mathematical induction (cf. Bussey 1917, Cajori 1918, Freudenthal 1953, Rabinovitch 1970, Fowler 1994, Unguru 1991, 1994). This disagreement is connected with the tendency to confuse history and heritage. Was there ever a proof by mathematical induction in ancient Greek mathematics? In Euclid's Elements, for instance? Historians of mathematics with a heritage view tend to answer these questions affirmatively.

Sabatai Unguru $(1991,1994)$ denies this categorically, on the ground that it is incompatible with the ancient Greek concept of number, according to which numbers are always determinate numbers of things as the units of a multitude. The multitudes are not seen as having, in general, in themselves or between themselves, a serial structure as being generated by a successor operation. A multitude always has, at least potentially, a manifestation as a multitude of independently given discrete things. In the arithmetical proofs in Euclid's Elements numbers are always represented as lengths of line-segments determined by their endpoints.

The mathematician Hans Freudenthal is one of those who have defended the opposite view about the origin of mathematical induction. In his article "Zur Geschichte der vollständigen Induktion" (Freudenthal 1953), he claims that the propositions IX, 8; IX, 9 and IX, 20 of Euclid's Elements (of which the last one is the proposition about the infinity of the prime numbers) are all proved by mathematical induction. The mathematician Paul Ernst (1982) agrees with Freudenthal, and in particular that the proof that there 
are infinitely many prime numbers uses mathematical induction. Let us examine Ernst's argument in some detail. Ernst asserts categorically:

Mathematical induction is implicit in some of Euclid's proofs, for example, in the proof that there exist infinitely many primes. This theorem is Proposition 20 in Book IX of Euclid, and translated it states "Prime numbers are more than any assigned multitude of prime numbers."

Euclid proves the proposition by letting A, B, C be the assigned prime numbers, and showing that $\mathrm{ABC}+1$ has a new prime factor $\mathrm{G}$. The conclusion of the proof reads: "Therefore the prime numbers A, B, C, $G$ have been found which are more than the assigned multitude of $A$, B, C. Q.E.D.”

However, Ernst claims that there is a gap in the proof. Something is missing between the last sentence in the proof (which concerns the particular case of the three assigned prime numbers $A, B$ and C) and the generality of the stated proposition that concerns any assigned multitude of prime numbers. According to Ernst,

This gap is bridged by the principle of mathematical induction. What Euclid proves, in fact, is that the existence of three primes implies the existence of four primes. The method of the proof is general, and can be used to prove the existence of $n+1$ primes from $n$ primes. However, Euclid lacks the algebraic language necessary for this more general induction step, and instead represents it by a particular case.

As pointed out by Mueller (1981), there is no indication that the multitudes in Euclid's Elements were conceived as having a serial order, as being generated by something like a successor operation, $n+1$.

But is Euclid's proof really a particular case of an "induction step" if no serial order is presupposed?

Quite contrary to what Ernst is suggesting, Euclid never writes $A B C+1$, for instance. He did not have a sign for the operation of addition (and he avoided multiplying numbers). He argues geometrically by extending the line-segment $\mathrm{ABC}$ by the unit linesegment. This is not just a difference in notation. It means that Euclid didn't have the notion of $n+1$ as an arithmetical operation, the 
successor operation as a symbol, which is a prerequisite for mathematical induction. A multitude, for Euclid, is just an aggregate of things as units, and a number is the number of the units of a multitude.

Ernst is reading Euclid's proof as if the generality of the proof comes from thinking of the assigned multitude of prime numbers $\mathrm{A}, \mathrm{B}, \mathrm{C}$ as an arbitrary sequence of prime numbers $P_{1}, P_{2}, \ldots, P_{\mathrm{n}}$ that is generated recursively by the method suggested in the proof. On the basis of this reading Ernst can say that "The method of the proof is general, and can be used to prove the existence of $n+1$ primes from n primes". But that was hardly Euclid's way of thinking about it. Euclid was thinking about it in geometric terms, where numbers are line segments.

Let us follow Ernst in 'modernizing' Euclid's proof (Elements, book IX, $\left.\int 20\right)$ by letting $\mathrm{P}_{1}, \mathrm{P}_{2}, \ldots, \mathrm{P}_{\mathrm{n}}$ be the assigned prime numbers. We shall prove that there are more prime numbers than these.

Consider the number $P=\left(P_{1} \times P_{2} \times \ldots P_{\mathrm{n}}\right)+1$.

$P$ is either a prime number or not.

If $P$ is prime the proof is complete since $P$ is then a prime number different from all the assigned prime numbers $P_{1}, P_{2}, \ldots, P_{n}$.

If $P$ is not a prime number it must have a prime factor $Q$ (by theorem VII, $₫ 31$ of the Elements). And this prime number must be different from all the prime numbers $P_{1}, P_{2}, \ldots, P_{\mathrm{n}}$ because otherwise it would be a factor of the unit, which is absurd.

Therefore, $Q$ is not one of the numbers $P_{1}, P_{2}, \ldots, P_{\mathrm{n}}$ and by hypothesis it is prime. So the prime numbers $P_{1}, P_{2}, \ldots, P_{n}, Q$ have been found which are more than the assigned multitude of prime numbers $P_{1}, P_{2}, \ldots, P_{\mathrm{n}}$.

Therefore, prime numbers are more than any assigned multitude of prime numbers.

Q.E.D.

The generality expressed by the variable $n$ in this proof is not the generality of a mathematical induction. There is no induction (even implicitly) in this modernized version of Euclid's proof any more than in Euclid's original proof. The generality of the variable $n$ only 
comes from the fact that the procedure of the proof is independent of the specific number of primes chosen as the assigned multitude of prime numbers.

If we would replace the expression $P_{1}, P_{2}, \ldots, P_{n}$ everywhere in this proof with Euclid's expression $A, B, C$ we would have Euclid's original proof (except that we have not written out the geometrical representation of the numbers, and we have defined the number $P$ by first multiplying the given prime numbers $P_{1}, \ldots, P_{n}$, which Euclid does not do). ${ }^{3}$ This shows that Euclid's assigned multitude of primes $A, B, C$, has the role of an arbitrary multitude of prime numbers in the original proof. One might even say that Euclid is taking the number 3 as a number variable. To understand Euclid's proof is also to understand that the assigned multitude of primes $A$, B, C can be replaced, for instance, by the multitude of five primes $A, B, C, D, E$, and then ' 3 ' is replaced by ' 5 ', but the proof procedure would still be the same.

Euclid's proof of theorem IX, 20, about the infinity of the prime numbers is not the only proof in the Elements where a general proposition about numbers is illustrated by a proof that deals with a specific finite multitude of numbers in which you are expected to see that the proof does not depend on the specific numbers chosen. Illustrating a general case in this way by dealing with a particular case is rather a common procedure in Euclid's Elements in general (not least in the geometrical theorems, where a specific drawn figure, a line-segment, a triangle or a circle, is used to prove general results about line segments, triangles and circles). The proposition IX, 10, for instance, begins as follows: "If as many numbers as we please beginning from a unit are in continued proportion, and the number after the unit is square, then all the rest are also square." Euclid begins the proof by saying: "Let there be as many numbers as we please, A, B, C, D, E, and F, beginning from a unit and in continued proportion, and let $\mathrm{A}$, the number after the unit, be square." Euclid is here dealing with the particular case of six

\footnotetext{
${ }^{3}$ Euclid considers numbers as lengths of line-segments and thus as being 'onedimensional'. He therefore avoids multiplication. Instead he uses Proposition 36 of Book VII, according to which "There is a least number which three given numbers measure", which is proved without using multiplication of numbers.
} 
numbers, with the required properties. What the phrase 'as many as we please' signifies is that you are supposed to see that the choice of a sequence of six numbers and no more (with the required properties) is not essential in the proof. And to see this is not an additional inferential step in the proof; it is to see the proof as a proof of the general result stated in the theorem.

From an Aristotelian point of view one might say that there is nevertheless a sense in which 'induction' is involved in this procedure of getting to see something general by dealing with particular cases, but it is not mathematical induction, and neither is it induction of empirical science. It is rather induction in the sense of Aristoteles' epagoge. Engberg-Pedersen (1979) argues convincingly that Aristotle had a unified conception of epagoge, which is not a type of inference. It is rather the exercise of the generalizing ability which Aristotle calls nous, a sort of intuition. Avoiding the word 'conclusion' which would suggest a type of inference, EngbergPedersen expresses the basic idea of this conception of epagoge as "attending to particular cases with the consequence that insight into some universal point is acquired" or, alternatively, "acquiring insight into some universal point as a consequence of attending to particular cases" (Engberg-Pedersen 1979: 305).

This use of epagoge to see something general by attending to particular cases is not an inference, but rather a kind of nondemonstrative procedure which is a routine procedure in mathematical reasoning, such as for instance in geometry when a specific, concrete triangle $\mathrm{ABC}$ is used as an "arbitrary triangle" in a proof of a theorem about triangles in general. So there is no gap in Euclid's proof in the sense that an inferential step is left out when he proceeds from particular cases to the universal point at the end of the proof of the infinity of prime numbers.

Did Euclid possess Aristotle's general notion of epagoge? It seems likely that Euclid as well as Aristotle learned this procedure of "acquiring insight into some universal point as a consequence of attending to particular cases" from mathematics (perhaps in their education at Plato's Academy). It seems likely that Aristotle's epagoge was then the result of extending the applicability of this procedure for getting insight into the 'universal in the particular' to topics 
outside mathematics. But why should the mathematician Euclid be interested in this general notion of epagoge? Well, Euclid was influenced by several features of Aristotle's philosophical doctrine (though not the theory of syllogisms). Euclid employs Aristotle's theory of statements with its distinction between axioms and postulates, and he follows Aristotle's dichotomy between discrete and continuous quantity, which persisted in mathematics up to the days of Descartes.

It is tempting to say that Euclid was a mathematician, not a philosopher, but the relationship between philosophy and mathematics was more complicated in ancient Greece. They did not have our sharp divide between philosophy and mathematics as two different and independent disciplines and professions.

Euclid's Elements is an exposition of the logical order of the fundamentals of elementary mathematics. So there is no doubt a logical-philosophical context present in the Elements. But that is not the only relevant context of the presentation in the Elements. The presentation also has pedagogical aims. The way in which epagoge may be present in the exposition is also influenced by the rhetorical-dialectical situation, where its aim is to get the readers and students of the Elements to accept the general points. It is not unlikely that Euclid sometimes says as much as is needed to achieve that aim. One reading of the basic idea of epagoge, discussed by Engberg-Pedersen that seems to be most appropriate here is the following:

leading another person, by pointing to particular cases, towards something katholou [universal] with the aim and consequence that he acquires insight into it. (Engberg-Pedersen 1979: 301)

Let us finally stress that to think about a multitude of prime numbers as an arbitrary finite sequence of primes, $P_{1}, P_{2}, \ldots, P_{n}$, is to situate it in an operational context that was foreign to Euclid. It is to take for granted how we operate with this symbol in the symbolic practice where we have access to the number-variable $n$ to express the form of a finite sequence. As stressed by Klein (1968) and Unguru (1975), the use of a letter as a number variable in this sense was foreign to ancient Greek mathematics. Alphabetic letters were used for numbers, but always for determinate numbers. Here 
we have one of the most essential features of the difference between the modern symbolic concept of number and the concept of number in ancient Greek mathematics. The symbolic concept is essentially connected with the use of a number variable to express the form of the result of performing an arithmetical operation. Without this use of a number variable, the precise sense of the notion of an arithmetical operation is lost. The generality expressed by the variable $n$ in a "proof from $n$ to $n+1$ ", which is the generality of a recursive pattern or rule, is the specific generality of mathematical induction and is bound up with the symbolic concept of number.

\section{Jacob Klein and the origin of symbolic mathematics}

The disagreement about the origin of proof by mathematical induction is only a particular case of a more general historiographical debate, or quarrel, about the history of ancient Greek mathematics that started with Sabatai Unguru's article "On the Need to Rewrite the History of Greek Mathematics", published in 1975. ${ }^{4}$ Unguru claims that lack of historical sense is a common feature of most mathematicians' readings of ancient mathematical texts in that they tend to read the ancient texts only from the point of view of modern mathematics. Unguru writes: "to read ancient mathematical texts with modern mathematics in mind is the safest method for misunderstanding the character of ancient mathematics ..." The historical approach, according to Unguru, is an approach that involves interpretation. It cannot "divorce itself from the attempt to unravel the original intentions of the text's author", which means that the interpreter has to be sensitive to the historical-cultural context.

Klein's 1968 book Greek Mathematical Thought and the Origin of Algebra is an important but rather neglected work in the history and philosophy of mathematics. ${ }^{5}$ Klein's historical approach anticipates Unguru's main point about the necessity to unravel the original

\footnotetext{
${ }^{4}$ See Kastanis, N. and Thomaidis, Y. (1991), "The term 'Geometrical Algebra', target of a contemporary epistemological debate", for a survey of this debate.

${ }^{5}$ A comprehensive survey of the work of Edmund Husserl and Jacob Klein on the philosophical foundations of the logic of modern symbolic mathematics appears in Hopkins B. C. 2011.
} 
intentions of the authors of classical Greek mathematical texts. Klein writes at the beginning of his book:

[...] most of the standard histories attempt to grasp Greek mathematics itself with the aid of modern symbolism, as if the latter were an altogether external "form" which may be tailored to any desirable "content". And even in the case of investigations intent upon a genuine understanding of Greek science, one finds that the enquiry starts out from a conceptual level which is, from the very beginning, and precisely with respect to the fundamental concepts, determined by modern modes of thought. To disengage ourselves as far as possible from these modes must be the first concern of our enterprise. (Klein 1968: 5)

Klein argues that the modern symbolic concept of number is not a further developed and extended version of the ancient Greek concept of number (Arithmos). The latter belongs to ancient Greek non-symbolic, ontological science. The modern symbolic concept of number is an essentially new concept, a concept in a new conceptual dimension, which was possible to articulate only together with the invention of the algebraic symbolism in the seventeenth century. According to Klein, the invention of the algebraic symbolism was an essential transformation in the sense that new techniques and operational practices were created as the basis for new conceptions. But an effect of this conceptual transformation was also that the original Greek understanding of numbers was lost, which is why Klein's 'intentional' historical method is needed.

But Klein's use of this method is meant to have not only historiographic interests and motives, he also claims that the understanding of the lost Greek conception of numbers may be helpful to resolve conceptual difficulties within modern mathematics and mathematical physics. He suggests that some of these difficulties have their source in the fact that "fundamental ontological science of the ancients is replaced by a symbolic discipline" (Klein 1968: 184). These difficulties are a main concern of mine in this essay. 


\section{The conceptual transformation towards algebraic symbolism}

The Greek mathematician who seems to have come closest to the conceptual transformation in which algebraic symbolism originated, was Diophantus of Alexandria (who lived in the third century AD, and who is sometimes called 'the father of algebra'). He was the author of a series of books called Arithmetica that deal with solving (what we call) algebraic equations. According to Klein, however, it is François Viète (Franciscus Vieta; 1540 -1603) who develops the logical and mathematical consequences of Diophantus' work, and who deserves to be called the 'inventor' of modern mathematics. An important step in Vieta's work was his innovative use of letters as parameters in equations. And it is Vieta who introduces the word 'symbol' (lat. Symbolum), and talks about the symbolic concept of number. ${ }^{6}$

Diophantus was working with an arithmetical calculus of determinate numbers, a logistice numerosa. Vieta advances Diophantus' problems by introducing a new 'general analytic' or an 'analytic art', using not number but merely 'species' or 'forms' - a logistice speciosa. The species or forms correspond to what we would call formulas or algebraic expressions. In the articulation of these symbolic forms, the use of letters as variables and parameters is essential.

The word 'species' or 'form' alludes to the 'eidos' of Greek philosophy, but it is important to understand how its sense has been transformed in Vieta's 'analytic art'. This is how Klein explains the difference:

$[\ldots]$ the "being" of the species in Vieta, i.e. the "being" of the objects of "general analytic," is to be understood neither as independent in the Pythagorean or Platonic sense nor as attained "by abstraction" $[\ldots]$ in the Aristotelian sense, but as symbolic. The species are in themselves symbolic formations $-[\ldots]$ They are, therefore, comprehensible only within the language of symbolic formalism. [...] Therewith the most important tool of mathematical natural science, the "formula", first becomes possible, but

\footnotetext{
${ }^{6}$ Klein says that 'The term 'symbolum,' used for the letter signs as well as for connective signs, originated with Vieta himself' (Klein 1968, 276).
} 
above all, a new way of "understanding," inaccessible to ancient episteme is thus opened up. (Klein 1968: 175)

The essential point of the conceptual transformation that Vieta accomplishes is that the concern with determinate numbers of units of measurement (of ancient non-symbolic arithmetic), is replaced by the forms expressed in an arithmetical-algebraic symbolism. So in a certain sense one might say that in the symbolic conception, form becomes the content. However, 'form' in this sense is not 'typographical form' or 'syntactical form' in the modern meta-mathematical sense. 'Form' in Vieta's sense is displayed in the operational practices.

The aspect of mathematics as activity is essential in the logic of symbolic mathematics. It is important to understand that the new arithmetical-algebraic system of Vieta (as well as the mathesis universalis of Simon Stevin, Descartes, and Wallis, who continue and complete Vieta's work) are not new theories of arithmetic, or new sciences of number (in the Aristotelian sense of 'science'), they are primarily new arts, new practices, new methods and techniques for dealing with problems, not only problems in 'pure mathematics' but also in cosmology, physics and astronomy. Vieta ends his work Isagoge by saying, "Analytic art appropriates to itself by right the proud problem of problems, which is: TO LEAVE NO PROBLEM UNSOLVED" (quoted in Klein 1968: 185; capitals in Vieta's original).

Vieta (like Descartes and other founders of modern science) had special interests in cosmological and astronomical problems, and his mathematical investigations are closely connected to his cosmological and astronomical work. The manner in which Vieta and other founders of modern science "set about attaining a mathematical comprehension of the world's structure betrays, from the outset, a different conception of the world, a different conception of the world's being, than that which had belonged to the ancients" (Klein 1968: 152). 


\section{Conflicting views of the role of symbolism in mathematics}

Let us return to the Unguru debate. B. L. van der Waerden, a professional mathematician as well as a historian of ancient mathematics, was one of the mathematicians who reacted immediately to Unguru's strongly polemic article with an equally polemic reply in which he accuses Unguru for overestimating the importance of symbolism in mathematics. Van der Waerden writes:

Unguru, like many non-mathematicians, grossly overestimates the importance of symbolism in mathematics. These people see our papers full of formulae, and they think that these formulae are an essential part of mathematical thinking. We, working mathematicians, know that in many cases the formulae are not at all essential, only convenient. (Van der Waerden 1975: 205)

According to Unguru (following Klein 1968), the emergence of algebra and symbolic mathematics in the seventeenth century, in particular the use of letters as variables and parameters, marks the beginning of an essential conceptual transformation of mathematics, while for van der Waerden the introduction of algebraic symbolism was only the invention of a more convenient notation to express a mathematical content that was in many respects the same as what it always has been. The content of Euclid's Elements II, for instance, is algebra according to van der Waerden and Freudenthal - it is 'geometric algebra', algebraic relationships expressed in geometric form due to the lack of the algebraic notation for expressing the algebraic content in classical Greek mathematics. ${ }^{7}$

In this controversy, I find myself in agreement with Klein, Unguru and their followers (with some reservations concerning Unguru's argumentation to be discussed later). The lack of sensitivity to, and interest in, features of the mathematical symbolism that are conceptually significant is not uncommon among 'working mathematicians' (and logicians), who have a tendency to think of a symbolism as a system of notations, a system of mere

\footnotetext{
${ }^{7}$ These conflicting views depend on the difference between a symbolism and a system of notation.
} 
typographical signs which are conceived in naturalistic terms, and this forces them to adopt a kind of dualism between form and content, expression and meaning, syntax and semantics. Carnap even said that "[s]yntax, pure and descriptive, is nothing more than the mathematics and physics of language" (Carnap 1959: 284). ${ }^{8}$

The lack of sensitivity to conceptually significant features of symbolism makes it difficult to distinguish between philosophical and mathematical problems. The attitude of a mathematician is often that something deserves to be called a real problem only when it can be dealt with and solved mathematically (this was, for instance, Hilbert's attitude to the consistency problem in his article "On the infinite" (1926)). Mathematicians are masters in using the mathematical symbolism, but not in reflecting upon this use. The latter requires that you pay attention to the symbolic practices from an outlook where the normal (silent) agreement in modern mathematical practices is put into focus.

Looking at ancient Greek mathematics from within the normal agreement in the practice of modern mathematics, there is always the risk of misunderstanding the non-temporality or timelessness of the sense or content of a mathematical rule or statement as if this timelessness were the infinite temporal duration of the content, the permanence of the content in time. But that the non-temporality of a rule or statement within mathematics is timelessness must be taken seriously; it is lack of any temporal significance or reference, including 'endless temporal duration' or permanence. I think that it is by taking timelessness as infinite temporal duration that Van der Waerden and Freudenthal are led to say that the algebraic content of an equation such as

$$
(\mathrm{a}+\mathrm{b})^{2}=\mathrm{a}^{2}+\mathrm{b}^{2}+2 \mathrm{ab}
$$

was present already in Euclid's times "at least implicitly", although this content was given a geometrical disguise in Euclid's Elements II. This is very doubtful in view of the fact that Euclid never multiplied geometric lengths or any other geometric magnitudes. If ' $a$ ' and ' $b$ ' are geometric lengths, the expressions ' $a$ ', ' $b^{2}$ 'and ' $a b$ '

\footnotetext{
${ }^{8}$ Carnap's notion of syntax, which is based on a naturalistic view of language, is very far from what Wittgenstein meant by 'logical syntax' in the Tractatus.
} 
seem not to have made sense to Euclid since they are of another dimension than ' $a$ ' and 'b'. It was not until Descartes' analytic geometry (which was based on Descartes' symbolic conception of geometry) that such 'mixtures' of arithmetic and geometry were made sense of.

The algebraic content of the equation above is inseparable from its algebraic proof, and its proof is the transformation of the lefthand side of the equation into the right-hand side using the rules of the algebraic calculus (that was set up and used not before the 17th century).

A mathematician, or rather a mathematical physicist, with sensitivity to, and interest in, conceptually significant features of mathematical symbolism was Heinrich Hertz. His attitude to the role of mathematical symbolism was therefore also quite the opposite of van der Waerden's, who takes mathematical symbolisms to be merely more of less convenient systems of notation. Hertz wrote:

We cannot escape the feeling that these mathematical formulas have an independent existence and an intelligence of their own, that they are wiser than we are, wiser even than their discoverers, that we get more out of them than was originally put into them. (Quoted in Bell 1937: 31)

Hertz' work on the mathematics of classical mechanics in which he showed how to deal with conceptual problems connected, for instance, with the notion of force of classical mechanics was an important and influential contribution to the symbolic point of view. I believe that Ernst Cassirer was right when he said: "Heinrich Hertz is the first modern scientist to have effected a decisive turn from the copy theory of physical knowledge to a purely symbolic theory" (Cassirer 1957: 20). ${ }^{9}$ Hertz saw the scientific theory as the application of a symbolic system, which is an autonomous entity in its formal aspect, independent of the empirical phenomena it is used to explain. By "the principles of mechanics", will be meant, says Hertz, "any selection of such and

\footnotetext{
${ }^{9}$ By the 'copy theory' Cassirer meant a view of physical theory that we find, for instance, in Ernst Mach's writings.
} 
similar propositions, which satisfies the requirement that the whole of mechanics can be developed from it by purely deductive reasoning without any further appeal to experience" (Hertz 1956: 4; emphasis added). Hertz showed that the problems connected with the notion of force do not relate to the empirical content of the problematic notions of mechanics, "but only to the form in which the content is represented", i.e. the conceptual problems are problems of the symbolism (Hertz 1956: 8). This is how Hertz himself motivated this feature of his work:

... the existing defects are only defects in form; [...] all indistinctness and uncertainty can be avoided by suitable arrangement of definitions and notations, and by due care in the mode of expression. (Hertz 1956: 9)

\section{Wittgenstein and symbolic mathematics}

The mentioned feature of Hertz' work deeply influenced Wittgenstein, not only the author of the Tractatus but also the later Wittgenstein. ${ }^{10}$ In the Big Typescript he writes:

In my way of doing philosophy, its whole aim is to give an expression such a form that certain disquietudes disappear. (Hertz) (BT, 421)

In this section, I will argue that the view of modern mathematics as symbolic mathematics was essential in Wittgenstein's approach to the problems in the discussion about the foundations of mathematics that begins in the late nineteenth century. Wittgenstein's interest in mathematical symbolism is conceptually more rigorous and sensitive than that of Klein and his followers in that he laid more stress upon the operational aspects of the mathematical symbolism as human practices the various features of which we do not survey even though we master the practices. Wittgenstein made the following, somewhat excessive, statement about the role of symbolism in mathematics: "Let's remember that in mathematics, the signs themselves do mathematics, they don't describe it" (PR 186). Inspired by Hertz, Wittgenstein said in the Tractatus that "My fundamental idea is that the 'logical constants' do

${ }^{10}$ This is argued in more detail in Stenlund 2012. 
not represent"( $T$ 4.0312). He would have said the same thing about the operations of arithmetic.

It is the operational aspect of a symbol, its function in the calculus, its role in the manipulation and transformation of expressions, which constitutes it as a symbol. So a symbolism is not just a system of notation in the typographical or linguistic sense (which is why the symbolic view of mathematics is not formalism or nominalism, as these notions are used in the literature of analytic philosophy $\left.{ }^{11}\right)$. This means, of course, that the new mathematical concepts (such as, for instance, the concept of an arbitrary finite sequence), emerged together with the new algebraic symbolism. The concepts could come into existence as new precise notions only when the operational practices of the new symbolism were in place. Or, rather, the invention of new notions was the invention of the new operational practices of the algebraic symbolism. It is not as if the new notions were invented in advance "in the minds of mathematicians" and were then given expression and application using the new algebraic notation. That is the sort of idealism or mentalism that Wittgenstein is constantly questioning (PG, 40).

Wittgenstein was questioning essentially the same mentalistic tendency in Frege when he wrote:

In attacking the formalist conception of arithmetic, Frege says more or less this: these petty explanations of the signs are idle once we understand the signs. Understanding would be something like seeing a picture from which all the rules followed, or a picture that makes them all clear. But Frege does not seem to see that such a picture would itself be another sign, or a calculus to explain the written one to us.

There is a tendency towards such a mentalism also in Klein's and Unguru's arguments that there were things that Greek mathematicians could not do because they did not have the concepts required. Klein and Unguru tend to argue as though there is always something mental, a mental cause, reason or ground, that makes people do what they do. But this idea is one of the most seductive sources of confusion. A lot of what we do, we do not do for any reason or ground, we just do as we have been trained to do.

\footnotetext{
${ }^{11}$ Such as for instance in Weir 2011.
} 
And our starting point is not 'complete passivity' but action. (As Goethe said: "Im Anfang war die Tat.")

One might say about many substantially new ways of thinking, new concepts, revolutionary changes in science, etc., which have emerged in the past, that they were once historically impossible, they were in sharp conflict with established notions and practices. But, nevertheless, they have happened, they have taken place, new operational practices developed, and subsequently history has been revised and rewritten. (A convincing criticism of the "argument from conceptual impossibility", as it has appeared in the Unguru debate, is given in Netz (2004)).

Wittgenstein emphasized the operational aspect of a symbolism, for instance, in the remark:

In order to recognize the symbol in the sign we must consider the significant use. (TLP 3.326) ${ }^{12}$

This can throw some light on Hertz' idea that the signs and formulas of mathematical symbolism have "an intelligence of their own, that they are wiser than we are, wiser even than their discoverers, that we get more out of them than was originally put into them". The 'hidden intelligence of formulas' is simply the manner in which a certain symbol or formula in its use is connected with so many other things in the arithmetical-algebraic system, which we don't survey and foresee even if we do master its use. This 'intelligence' seems to be hidden only because we do not survey the possible uses of the formula even if we do master them in practice. This is true especially of the 'moves of the game' at the most basic operational level where there is complete agreement in action among mathematicians. These moves and features of the calculus therefore tend to be dismissed as 'trivialities' by mathematicians. But such trivialities are precisely the topic of Wittgenstein's investigations about the foundations of

\footnotetext{
${ }^{12}$ The original German version of this remark is "Um das Symbol am Zeichen zu erkennen, muss man auf den sinnvollen Gebrauch achten." I prefer Ogden's translation of this remark. The Pears and McGuinness translation, "In order to recognize a symbol by its sign we must observe how it is used with a sense", can be read as though the sign has already got a sense (in some sort of 'semantics') prior to and independently of its use.
} 
mathematics. This is why it is so difficult to understand what he is up to in some of his remarks on the foundations of mathematics. His topic, 'the nature of mathematical symbolism', is a non-topic for the mathematician. In Philosophical Grammar Wittgenstein remarks: "The philosopher only marks what the mathematician casually throws off about his activities" (369).

Wittgenstein's conception of mathematics, already from the beginning in the Tractatus, has much in common with what has been called symbolic mathematics. I think that this is true of the early and middle as well as the late Wittgenstein. I am inclined to say that for Wittgenstein, the most authentic form of mathematics in modern times is symbolic mathematics. ${ }^{13}$ The symbolic view of mathematics offers us a perspective from which the unity of Wittgenstein's philosophy of mathematics becomes apparent.

A clear manifestation of Wittgenstein's symbolic point of view is his claim that mathematical propositions are not 'real' propositions. According to Wittgenstein, they don't have a descriptive content; they do not describe real states of affairs. Already in the Tractatus, mathematical propositions were called "pseudo-propositions". And around the beginning of the 1940's, he expressed a symbolic, non-ontological conception of mathematics as follows:

Let us remember that in mathematics we are convinced of grammatical propositions; so the expression, the result, of our being convinced is that we accept a rule.

Nothing is more likely than that the verbal expression of the result of a mathematical proof is calculated to delude us with a myth.

I am trying to say something like this: even if the proved mathematical proposition seems to point to a reality outside itself, still it is only the expression of acceptance of a new measure (of reality).

Thus we take the constructability (provability) of this symbol (that is, of the mathematical proposition) as a sign that we are to transform symbols in such and such a way. (RFM III, $\$ \$ \$ 26-7$ )

\footnotetext{
${ }^{13}$ Here I am using the word 'authentic' in more or less the same sense as when we say that chemistry is an authentic natural science today, which alchemy is not.
} 
This is something that cannot be made much sense of within a philosophical vocabulary based on the foundational status of mathematical logic, where all possible propositions are propositions in the ontological sense. They have a descriptive content and are about something in a 'referential sense'. There is no place in the vocabulary for propositions in any other sense. The closest one can come to propositions in some non-ontological sense are propositions in the "nominalistic" sense that are merely about concrete signs, so-called 'syntactical propositions'. One is forced to see Wittgenstein's philosophy of mathematics as some superficial kind of formalist view in which mathematics has been deprived of all meaning.

But as Wittgenstein said in the last quotation, if he is depriving mathematics of something in his critique of foundations, it is the (often misleading) prose that accompanies the mathematical calculi, and he is doing so in order to clarify the sense that mathematical notions have within the calculi.

\section{Symbolic arithmetic and the place-value system of numeration}

As mentioned, I am inclined to agree with Unguru (and his followers) that there was no proof by mathematical induction in ancient Greek mathematics. And I think that this circumstance is connected with the fact that in ancient Greek mathematics (by the time of Euclid and Archimedes), one did not have the full placevalue system for numbers, and 0 and 1 were not seen as a numbers. My suggestion is that the ideas of an arbitrary finite sequence and finite iteration of symbolic arithmetic, which are preconditions of proof by mathematical induction, had their origin in the emergence of the place-value system for numbers, which was referred to as the Arabic ciphers. Ortega y Gasset (1971: 52) reports that Leibniz, in his published correspondence, "called attention to the fact that Arabic ciphers have the advantage over Roman ciphers of expressing the "genesis" of a number and thereby of defining it" (cf. Leibniz, Matematische Schriften, vol. IV, 455ff.).

Of particular importance was the decimal place-value system, also called the Hindu-Arabic numeration system (which was 
imported to the west in the middle ages from Arabic sources and which subsequently became our normal way of writing numerals). Boyer (1968: 234) mentions that the Hindu mathematician Aryabhata, who was active in the fifth century, used a form of the decimal place-value system and in his writings we find the phrase:

from place to place each is ten times the preceding.

This phrase indicates the principle of the generation of the bases of the decimal place-value system, i.e. that the places are Units, Tens, Hundreds, Thousands, Ten Thousands, and so on. Here the phrase "and so on" is not an abbreviation for something that could be written out in full as when we say "A, B, C, and so on" for the sequence of letters of the alphabet. Aryabhata's phrase suggests the idea of arbitrary finite iteration of an operation, in this case the operation of multiplying the base of the preceding place by ten.

In the fully developed decimal place-value system for integers, a number is written as a finite sequence or string of digits taken from the list of digits $0,1,2,3,4,5,6,7,8,9$. Each digit has its unique place within the sequence as a whole. Since it is only single digits that occur as the terms of the sequence, there is no need to separate the places of the sequence by means of commas or some other device than juxtaposition. The total value of a numeral, as a sequence of digits, is calculated in this notation by additions and multiplications. For a two-digit numeral, 23 for instance, we have

$$
23=(2 \times 10)+(3 \times 1) .
$$

For a three-digit numeral, 517 for instance, we have

$$
517=(5 \times 100)+(1 \times 10)+(7 \times 1)
$$

and for a four-digit numeral, 3702 say, we have

$$
3702=(3 \times 1000)+(7 \times 100)+(0 \times 10)+(2 \times 1)
$$

and so on. In the second example ' 1 ' is used as a number, and in the last example ' 0 ' is used as a number. The numbers ' 0 ' and ' 1 ', which were not numbers according to the Greek notion of number (arithmos), have clearly important functions in the decimal placevalue system. 
Neither the late ancient Greeks nor the Hindu-Arabic mathematicians had the symbols I have used here for equality, addition and multiplication. Equations, as well as addition and multiplication were expressed in verbal language, in mathematical prose (to use Wittgenstein's expression). The algebraic symbolism was not yet invented and the presentation was, as one says, rhetorical. And, of course, they did not have anything like the following algebraic symbol for the 'general case' of a number in the decimal place-value system:

$$
a_{k} a_{k-1} \ldots a_{0}=a_{k} 10^{k}+a_{k-1} 10^{k-1}+\ldots+a_{0} 10^{0}
$$

where $0 \leq \mathrm{a}_{i}<10$ and $\mathrm{a}_{k} \neq 0$. It is important to realize that this expression belongs to a symbolic system, an operational practice that did not exist in Greek or Hindu-Arabic mathematics, but only in modern mathematics. One essential symbolic feature of this equation is the use of the number-variable $k$. For a sufficiently large value of $k$, the numeral $a_{k} a_{k-1} \ldots a_{0}$ would not have a reading in ordinary language as my examples 23, 517 and 3702 all have. But even without this expression for the general case, it can be seen on the basis of examples, being particular cases, that this method of numeration stipulates no limit to the length of the expression for a number, i.e. to the number of places occurring in it. Each number is uniquely determined by the method for its construction in this system of numeration.

With the place-value notation, one was in possession of the operational germ of the arithmetical idea of "and so on ad inf." (if not the precise arithmetical concept, which required the arithmetical-algebraic symbolism), and also the operational germ of the ideas of finite iteration, and a finite sequence, and thereby also the germ of recursive proof or proof by mathematical induction. The word 'infinity' in the phrase "and so on ad inf." here simply means that no finite sequence of digits is excluded as an expression for a number. It is not a feature of this system of notation for numbers that a number must be the number of things of some given multitude of things. A numeral in this system is a finite sequence of digits, which is a symbol for a number determined by the rules for calculating in the system. 
It should be clear that the sense of number and finiteness suggested here is essentially different from the notion of number and finiteness of ancient Greek mathematics, since it was essential for the Greek concept of number (Arithmos), that a number is a number of things (units) of a multitude.

The problem of so-called effective calculability discussed in connection with Church's thesis in modern mathematical logic arises only for the notion of finiteness of modern symbolic mathematics, according to which a verbal expression such as "can be carried out in a finite number of steps" has a kind of non-literal, symbolic sense that did not exist for the Greeks. In ancient Greek logistics one was surely concerned very much with 'practical effective calculation procedures', but not with the calculability of the number-theoretic functions, that are discussed in connection with Church's thesis.

The features of the decimal place-value system of numeration I have stressed here points towards the symbolic notion of number and finiteness that begins to emerge in the work of Vieta, Stevin, Descartes and Wallis in the sixteenth and seventeenth centuries. Of particular importance in this respect was Stevin's work. ${ }^{14}$ In 1585 he published a pamphlet, De Thiende ("Art of Tens") in which he used not only the decimal place-value system for integers, but also for decimal fractions. The Arabs and Chinese knew about decimal fractions earlier, but they were not used very much. Stevin compares Arab and Greek mathematics and his comparisons are often to the disadvantage of Greek mathematics. In Stevin's view the most important historical roots of modern mathematics are not in Greek mathematics, but rather in Hindu-Arabic mathematics.

Stevin's pamphlet was very influential. He established the use of decimals in everyday mathematics, demonstrating the simplicity and advantage of the system. In the introduction to De Thiende he predicted that using decimal fractions in coinage, weights and measures, etc. would be one day universally accepted - a prediction that has come true to a great extent (even if it is not universally accepted). Stevin was very much what we would call an 'applied

\footnotetext{
${ }^{14}$ Simon Stevin (1548-1620) was a Flemish mathematician and military engineer.
} 
mathematician'. As Klein puts it: "Stevin consciously breaks with the traditional forms of science and puts his 'practical' commercial, financial, and engineering experiences into the service of his 'theoretical' preoccupation - as, conversely, his 'theory' is put to use in his "practical activity"' (Klein 1968: 186). Thus, for instance, he was the first to explain the tides using the attraction of the moon. In 1586 (three years before Galileo) he reported results of his own experiments to the effect that different weights fell a given distance in the same time. He wrote on astronomy and strongly defended the sun system of Copernicus.

Unlike Vieta, who expressed himself very respectfully with regard to Greek mathematics, Stevin is very critical, and in particular about the weaknesses and mistakes he finds in Greek arithmetic. (An exception here is Archimedes, whose work Stevin admired.) The Greek view that the number 'one', or the 'unit', is not a number but rather the principle or arche (the beginning) of number, was according to Stevin one such mistake that he examines at great length and rejects. He also made a strong plea that all numbers such as square roots, irrational numbers, negative numbers etc. should be treated as numbers and not be distinguished as being 'different in nature'. As van der Waerden puts it: "For Stevin, the real numbers formed a continuum. His general notion of real number was accepted, explicitly or tacitly, by all later scientists" (Van der Waerden 1985: 69).

Klein's detailed account of Stevin's criticism of the Greek concept of number shows that the criticism is firmly based on the symbolic concept of number manifest in the decimal place-value system.

\section{Rabbi Levi ben Gerson: towards precise notions}

Looking at the historical development of mathematics, one can see that many mathematical concepts, methods, and techniques that were given precise mathematical sense in the symbolic systems that started to emerge in the seventeenth century had forerunners, but, of course, forerunners that were less precise by the standards of modern mathematics. This is also true of the method of using recursion in proofs. One mathematician who used what one would 
be inclined to call, "proof by recursion" or "proof by induction", quite systematically was Rabbi Levi ben Gerson. ${ }^{15} \mathrm{He}$ proved several theorems on the commutative and associative properties of multiplication and on permutations and combinations using recursive procedures.

What should be noted first of all is that ben Gerson is using the decimal place-value system for numbers in computations - not however with the Hindu-Arabic notation, but with the first nine Hebrew letters for the digits 1, .., 9, and a circle for zero. Following Euclid he also represents numbers as line segments, i.e. $A B$ for the line segment with endpoints $A$ and $B$ but, at the same time, arbitrary numbers are also represented by letters $a, b, c, \ldots$ In his proof of the theorem that the number of permutations of $n$ elements is the product with the factors $1,2, \ldots, n$, he states (what we call) the induction-step in prose as a theorem, and then he reformulates it as follows:

Let the elements be $a b c d e$ and their number be $n$ and let $m$ be the successor of $n$. Let the number of permutations of $a b c d e$ be $t$. Adding one member to the set $a b c d e$, we obtain $a b c d e f$ containing $\mathrm{m}$ elements. We say that the number of permutations of $a b c d e f$ is equal to the product of $t$ by $m$.

It is clear, from the context, that Levi ben Gerson is not concerned with the particular case of a sequence of five numbers when he writes $a b c d e$ (in the sense in which Euclid was indeed concerned with the particular case of a sequence of three prime numbers when he wrote "Let $A, B$ and $C$ be the assigned prime numbers" in

\footnotetext{
${ }^{15}$ Levi ben Gerson was born in Languedoc in 1288, and was a Talmudist, philosopher, Biblical commentator, mathematician, astronomer, and physician. He wrote in Hebrew and completed several mathematical works. For instance, a commentary of several books of Euclid's elements and a work called Maasei Hochev, the title of which is said to mean "the work of the calculator". In the first (theoretical) part of the book, sixty-eight propositions are given general proofs, and the second part gives instructions for solving numerical problems in adding, subtracting, multiplying, but also in summing arithmetical and geometric series, and in combinations, permutations, and proportions, and in extraction of square and cube roots. In the Maasei Hochev, which was completed in 1321, we find repeated use of recursion in proofs. (My account of Levi ben Gerson and his work is based on Rabinovitch (1970)).
} 
the beginning of his proof of the infinity of the primes). Ben Gerson tends to use the expression

$$
a b c d e
$$

as we would use an expression like

$$
a, b, c, d, \ldots, e
$$

where the three dots is an abbreviation for the (n-5) members of the sequence that have not been written out (and ignoring that ' $\mathrm{e}$ ' comes immediately after ' $d$ ' in the alphabet). So to some extent one might say that he had the germ of the notion of an arbitrary finite sequence. Not, however, as a notion belonging to a developed calculus of finite sequences. He does not seem to have had a clear notion of the form of a finite sequence, or an accurate symbolism for finite sequences. Neither did he have a satisfactory notion of the successor operation (by the standards of modern mathematics). When he says "let $m$ be the successor of $n$ ", he somehow thinks of it as an external relation between two given numbers, rather than as an operation on numbers which is given by its form $n+1$, where ' $n$ ' is a number variable. One reason for this may have been that he didn't have symbols for addition (and multiplication) as operations. Addition, multiplication and equality were expressed in verbal language as in Greek mathematics. For this reason there is a great lack of perspicuity (surveyability) in ben Gerson's statement of theorems and proofs. Rabinovitch points out that "it is quite difficult to read even relatively simple statements where every plus sign must be written out in words" (Rabinovitch 1970: 239). Here one could ask oneself, if this difficulty is due to a mere notational inconvenience or if it is rather a conceptual difficulty. To what extent is the perspicuity of a proof a part of its essence as a proof? One gets the impression that there is a tension in ben Gerson's mathematics between the verbal-geometric perspicuity of Euclid, and the algebraic-symbolic perspicuity connected with the placevalue notation and the use of letters as variables. Consider for instance, Maasei Hoshev, Proposition 41:

The square of the sum of the series of integers beginning from one up to a given integer is equal to the cube of the given integer plus the 
square of the sum of the series of integers from one up to the predecessor of the given integer.

In modern symbolism this proposition would be expressed:

$$
\left(\sum_{1}^{n} i\right)^{2}=n^{3}+\left(\sum_{1}^{n-1} i\right)^{2}
$$

Already when he reformulates the original proposition in the beginning of the proof, ben Gerson moves closer to the algebraicsymbolic perspicuity by using letters for arbitrary numbers of a series.

In ben Gerson's proofs, in which we recognize a use of recursion and are inclined to call them proofs by induction, he often illustrates the proof with more cases than needed (in the proof), i.e. not only for the base $n=1$, but also for $n=2, n=3, n$ $=4$. What he seems to want to illustrate here is how the result 'extends to infinity' like a ladder or a spiral. In connection with the (recursive) proof of the theorems on the commutative and associative properties of multiplication, he says:

In this manner of rising step by step, it is proved to infinity.

So the method of rising step by step is ben Gerson's name for what later has been called "the method of proof by mathematical induction". Unlike the modern statements of the method it is not defined or made precise in some mathematical calculus or system. It is rather what one perhaps would call "an intuitive notion". The name rising step by step is an ordinary language simile that captures a similarity between procedures in different proofs by induction. ${ }^{16}$

So ben Gerson, unlike Euclid, was using letters $a, b, c, \ldots$ for arbitrary numbers, i.e. these letters are used as parameters. And his use of the letter $n$ and $m$ in his proof about permutations are number variables. The recursion in the proof ('the induction step') is carried out on these variables. He also seems to have had a notion of an arbitrary finite sequence, even if his symbolism is not satisfactory. I don't think that it is farfetched to believe that his

\footnotetext{
${ }^{16}$ According to Rabinovitch (1970: 245) 'rising step by step' is a translation of the Hebrew word Hadragah. A noun formed from the same root occurs in the Bible where it is taken to mean cliffs that appear like rising stairs.
} 
familiarity with and use of the place-value system for numerals is one important thing that takes ben Gerson's mathematics closer to modern symbolic mathematics.

My point with the previous discussion of mathematical induction is not mainly historical, its point is rather to show what difference the symbolic point of view makes, by giving some examples of what sort of differences 'make the difference'.

Ben Gerson had a notion of mathematical induction, of finite sequences etc., which were not clear enough by our standards. They rest on vague analogies expressed in prose. But we are nevertheless inclined to call it a beginning of the development towards precise notions. However, we could also say that he had the beginning of a symbolism for these notions, but one that was not accurate. It may then seem as though we have two different kinds of inaccuracies, one having to do with content and the other with form. It is important to realize that this alleged difference is a mistaken idea. It is one and the same inaccuracy. When you have found an accurate symbolism for a notion, you have also become clear about the content of the notion.

\section{Ordinary verbal language and mathematical symbolism}

It was an important feature of Greek mathematics that the language of mathematics be continuous with and in proximity with ordinary verbal language. This is also argued by Klein (1968). It seems to be part of what Klein expresses as follows:

Greek scientific arithmetic and logistic are founded on a "natural" attitude to everything countable as we meet it in daily life. This closeness to its "natural" basis is never betrayed in ancient science. (Klein 1968: 63)

The closeness to its "natural" basis of everyday life is a feature of Greek mathematics that stands in sharp contrast to modern symbolic mathematics. There is a striking contrast in this respect even when we compare Greek science and modern science in general. In contemporary popular science there is a clear tendency to relinquish what "we meet in everyday life" and even to give oneself up to mythology. 
Articulating modern mathematics in ordinary verbal language by assigning a place for mathematical propositions in the general category of propositions expressed by declarative sentences of natural language, have often resulted, not in "closeness to the natural attitude of everyday life", but on the contrary in mythological ways of thinking such as for instance the 'nonlinguistic' Thoughts of Frege (which have their special Wirklichkeit as entities of "The Third Realm"), ${ }^{17}$ or the ontological mythologies of transfinite set theory of Cantor and Gödel.

Modern logicians are more ontologically extravagant than Aristotle, who says that "The general propositions of mathematics are not about separate things which exist outside of and alongside the [geometric] magnitudes and numbers, but are just about these; not, however, insofar as they are such as to have a magnitude or to be divisible [into discrete units]" (Metaphysics M3, 1007b 17-20). The general propositions that Aristotle had in mind here are, for instance, the axioms or "the common notions" and the theorems of Eudoxus" theory of proportions.

The ontological views of Aristotle are a hard topic, however. He rejected Plato's doctrine that numbers have an independent existence, and claimed instead that quantity, magnitude and number exist within the phenomena we perceive with our senses. The number three is not detached or separated from a multitude of three apples. But how can they then be objects of knowledge (episteme) in arithmetic as theoretical science? This question is what Aristotle answers by what has been called his "theory of abstraction".

Having said that quantity is inseparable from sensible things, it is somewhat surprising to find Aristotle saying that arithmetical science nevertheless studies the numbers as if they were separated from the objects of sense. Aristotle claims that "It [science] thinks the mathematical objects which are not separate as separate when it thinks them" (On the Soul, Г 7, 431b 15f.). And this is accomplished

\footnotetext{
${ }^{17}$ Frege (1979: 269), writes: "There is no contradiction in supposing there to exist beings that can grasp the same thought as we do without needing to clad it in a form that can be perceived by the senses. But still, for us men there is this necessity."
} 
by abstraction in which "their separate mode of being arises from being "lifted off", "drawn off", "abstracted" (Klein 1968: 104). "The mathematician makes those things which arise from abstraction his study, for he views them after having drawn off all that is sensible ..., and he leaves only the 'how many?' and continuous magnitude."(Metaphysics K 3, 1061 a 28ff.)

Abstraction is, however, not meant to be a sort of psychological procedure resulting in mathematical objects as mental constructions.

Klein summarizes Aristotle's ontology of mathematical objects as follows:

If the reduction [in the abstraction process] goes so far that things are no longer regarded even as "mere bodies" but only as "items," these things have been transformed into "neutral" monads. Just this "neutrality" of things which have withered away into mere countable "items" constitutes the "purity" of the "arithmetic" monads and turns them into the noetic material which underlies scientific study. (Klein 1968: 105)

So we can understand Klein's statement that with Vieta's symbolic approach in his Analytic Art "a new way of 'understanding,' inaccessible to ancient episteme is thus opened up".

Let us return to Klein's claims that Vieta is the "inventor of modern mathematics" and that "modern mathematics is symbolic mathematics". Klein's claims are quite extensive and strong. Presumably, he does not want to say that modern mathematics has reached full realization and understanding of its symbolic nature. That this is not what he is saying seems to follow from his statement about the "ontological presuppositions [that] are left unclarified", in modern mathematics and mathematical physics.

Despite the transformation of mathematical thought that takes place with the work of Vieta, Stevin, Descartes and Wallis, it seems to me that there are important features of Greek non-symbolic ways of thinking that were passed on, rather unaffected by the symbolic transformation, to modern times through two very influential works, namely Aristotle's logical doctrine and Euclid's Elements (and many features, if not all, of Aristotle's logical doctrine 
are part of the philosophical context in Euclid's Elements). ${ }^{18}$ The great influence of Euclid's Elements, even in modern times, has made people compare its influence with that of the Bible. It has been said that no other book, except the Bible has as many translations, editions and commentaries as the Elements. Calinger points out about the Elements that "Its geometrical conception of mathematics greatly influenced the natural sciences - in medieval Arabic and Latin natural philosophy as well as in Isaac Newton's Principia of 1687, which follows the format of the Elements. Its conceptions were basic to Kant's Critique of Pure Reason, published in 1781" (Calinger 1999: 132-3).

Klein would perhaps object that our understanding and reading of Euclid's Elements since the seventeenth century is, nevertheless, imprinted by our loss of understanding of ancient Greek mathematical thinking. In Greek mathematics one had the conscious attitude that natural language referring to ordinary immediate experience is the basic linguistic framework. It has priority over other linguistic domains. Klein is certainly right that the reference to ordinary immediate experience as the basic source of fundamental mathematical concepts is something that gets lost, or is abandoned, in the transformation that takes place in the seventeenth century. It was this step in particular that made it possible for seventeenth century mathematics to transgress the boundary line between discrete and continuous quantity - a boundary line which we find in Aristotle and Euclid and their followers. But what is still not abandoned is the tendency to give meaning and significance to basic notions in mathematics and formal logic by translation or paraphrase into verbal language (to which I count what is often called "informal mathematical language", or, in Wittgenstein's words "mathematical prose").

Another thing that was transferred to modern times from the Aristotelian-Euclidian tradition is a philosophical attitude to formal

\footnotetext{
${ }^{18}$ See Mancosu (1996: Ch. 1 and 4.) Mancosu argues convincingly that "the Aristotelian epistemological framework was pervasive in the seventeenth century and very influential indeed in later centuries" (Mancosu 1996: 92). By the "Aristotelian epistemological framework" Mancosu means primarily what we find in Aristotle's Posterior Analytics.
} 
logic, what I would like to call the foundational status of (formal) logic, which involves at least the following things: First, logic is concerned with judgments or propositions originally connected with the episteme of the Aristotelian ontological concept of a science. In this sense a science and its propositions are always about a certain subject matter that we have access to through a process of abstraction. Geometry and its propositions, for instance, are about continuous quantity, which we encounter in nature. This ontological conception of propositions is present in mathematics as much as in physics and biology. Secondly, to the foundational status of formal logic belongs also the idea that logic displays the form of judgments or propositions that is essential for their being true or false. This means in particular that a logically wellarticulated proposition carries its meaning or logical content by itself as a proposition, regardless of its context of use.

What I want to argue is that the foundational status of logic, Aristotelian logic as well as modern formal logic, is intimately connected with the translation (or paraphrase) of the basic notions and rules of the logical calculi into natural language, and thus into a non-symbolic linguistic framework. The prose-translations, or the natural language readings, of the basic logical notions and formulas of formal logic tend to become ritualized and acquire a normative role for what constitutes the logical content of propositions. (In learning to formalize sentences of ordinary language using the propositional or the predicate calculus in contemporary introductory logic courses, students are initiated in these ritualistic reading techniques. To learn to disregard the context of use of sentences is an important part of learning these paraphrasing techniques.) Being articulated in ordinary language, it now appears as though the logical notions and rules are already present in ordinary language, as a hidden or concealed logical core of ordinary language that is made explicit through formalization. But the normativity of the prose-readings of logical notions and formulas was not a discovery about ordinary language; they were adapted to the formal rules of the logical calculi. And it is a part of this adaptation to disregard how the precise conceptual content of sentences depends upon the context of their use. 
What I have said here about the role of verbal language may seem to be in conflict with Frege's logical doctrine in one respect. The proper subject matter of logic, according to Frege, is not sentences of natural language but Thoughts, which are sometimes said to be 'non-linguistic' entities. For Frege it is Thoughts that are the subject matter of logic, that have a logical structure and stand in logical relations to one another. A Thought is about a determinate subject matter, and it says something true or false about that subject matter. - But how can a Thought say something about a subject matter if it is 'non-linguistic', if it is not articulated by signs of some sort? A determinate Thought has to be expressed as a sentence of a language, if it is to be a determinate thought at all. ${ }^{19} \mathrm{~A}$ Thought is really what Frege earlier called the Sinn of a sentence of language.

The propositional calculus and the predicate calculus are calculi. It would be possible to present the systems of formal logic as pure calculi, in which the basic logical notions are deprived of all meaning that comes from the translation and paraphrase into natural language (i.e. the reading of ' $\mathrm{f}(\mathrm{a})$ ' as 'a has the property $\mathrm{f}$, ' $\neg \mathrm{A}$ ' as 'It is not the case that A', 'A \& B' as 'A and B', ' $\exists x f(x)$ ' as 'there exists an object $\mathrm{x}$ which has the property $\mathrm{f}$, etc.). In such a presentation of formal logic as a pure calculus, the basic logical operations are symbols (not just signs; remember that a symbol is determined by how we operate with a sign in the calculus). The different signs ' $\neg$ ' and ' ', for instance, have been used for the same symbol. If we call that symbol 'negation', we must keep in mind that this word only signifies a symbol in the pure calculus; its sense does not come from a translation of the signs ' $\neg$ ' or ' $\sim$ ' as 'not' or as 'it is not that case that' in natural language.

One could make the same point by saying that it would be possible to do with the systems of formal logic what Hilbert did with Euclidian geometry in his Grundlagen der Geometrie. Hilbert presented Euclidean geometry as a system in which the basic notions (e.g. 'point', 'line', 'plane', 'between', etc.) are deprived of

\footnotetext{
${ }^{19}$ Frege states explicitly: “...that a thought of which we are conscious is connected in our mind with some sentence or other is for us men necessary" (Frege 1979: 269).
} 
the meaning that comes from their use in informal geometrical language, (which is often called the 'intuitive meaning' of these words). So the only 'meaning' that the basic notions have in the system is the one that comes from the axioms and rules that define the system. ${ }^{20}$ By viewing Euclidian geometry as a pure calculus we would go further than Hilbert, who was still following the logical tradition in presenting the Euclidian geometric system as a theory about some 'unspecified things', external to the Euclidean calculus. According to Hilbert, he had presented geometry as a "pure mathematical science" in Grundlagen. By viewing the system as a pure calculus, the axioms get the role of rules for the operation with the basic notions and the signs of the calculus (which include geometric figures).

In such a presentation of the logical systems as pure calculi, they are mathematical symbolisms, and they would deserve the name "symbolic logic". Formal logic as symbolic logic in this sense has no longer the foundational status I mentioned before. The foundational claims disappear when the logical symbol's connection with informal verbal language is cut off. They are just mathematical symbolisms side by side with other mathematical symbolisms without any exceptional position among the great variety of mathematical symbolic systems.

In many purely mathematical results about logical systems, in so-called 'metalogic', only such features that belong to the system as a pure calculus or a mathematical symbolism are actually used. But in presentations of modern logical systems, one tends to state and present their mathematical properties as if the systems are inseparable from the translation of the signs into natural language (or mathematical prose), i.e. as if the logical operations must have the sense that comes from their translation into natural language. The reason for this is of course that one wants to adhere to the

\footnotetext{
${ }^{20}$ Freudenthal (1962: 618) expressed the significance of Hilbert's Grundlagen by saying that with Hilbert "[...] the bond with reality is cut. Geometry has become pure mathematics. The question whether and how to apply it to reality is the same in geometry as it is in other branches of mathematics. Axioms are not evident truths. They are not truths at all in the usual sense."
} 
foundational status of formal logic according to which the propositional calculus, for instance, is concerned with propositions in the ontological sense; they are understood as being about some sort of reality external to the calculi that make them true of false. But as a pure calculus the propositional calculus is only concerned with formulas, and their translation or reading as (forms of) English sentences is not part of the rules of the calculus.

If the logical symbols' connection with the natural language readings of them were cut off, one would also undermine the philosophically suggestive prose reading of most results in metalogic, i.e. results about 'consistency', 'soundness', 'completeness', 'incompleteness', 'decidability', 'undecidability', etc. Confronted with the threat that the alleged philosophical significance of, for instance, famous results such as Gödel's incompleteness theorems gets lost, logicians will hold on to the foundational status of formal logic, and to the ritualized prose readings of the logical symbols.

The point of presenting a logical system as a pure calculus would be to show that the foundational status of formal logic, and the prose readings of the logical symbolism, is not a (mathematically) necessary feature of it. It shows how the ontological conception of propositions of mathematics is intimately connected with the translation of the logical operations into verbal language. So in a certain sense one might say that the nonsymbolic, ontological conception of mathematical propositions rests upon giving informal mathematical language a foundational significance. ${ }^{21}$ I think that this feature belongs to the heritage from the Greeks (Aristotle), and it stands in sharp contrast to the symbolic conception of mathematics.

The most obvious way in which a branch of mathematical logic rests upon the standard readings, or translations into verbal language of the expressions and formulas of the predicate calculus

\footnotetext{
${ }^{21}$ Here it is instructive to look at the debate between Hilbert and Frege (in Frege 1980). It is clear that Frege argues as if the presentation of a mathematical system (geometry as well as logic) as a pure calculus is impossible, because, according to Frege, the meaning of the basic notions that comes from the translation into informal language cannot be disregarded.
} 
is in so-called 'model-theoretic semantics', where one starts out with a notion of 'truth in a structure'. Such a structure has a domain of objects that are values of the bound variables. Via the natural language reading of formulas, a formula becomes a proposition about these objects that is true or false in the structure. If the objects are numbers, the formulas are translated into arithmetical propositions. It is clear that the ontological conception of arithmetic is built into this approach. One gets the impression that the standard verbal reading of the formulas of the predicate calculus was an important source of inspiration in the invention of model-theoretic semantics.

Returning to Klein's claim that the essence of modern mathematics is symbolic mathematics, it is clear that this claim does not apply to modern mathematical logic as it is understood and used in the discussion about the foundations of mathematics since the beginning of the twentieth century. And this foundational discussion has dominated (and thereby also delimited) the discussion in the philosophy of mathematics since then. All positions in this philosophical discussion (e.g. realism, Platonism, intuitionism, logicism, formalism, structuralism, etc.) take for granted the ontological conception of a proposition with roots in the logical tradition, and mathematics is seen as a kind of 'natural science of mathematical objects', whether they are platonic objects or mental constructions. ${ }^{22}$ In the symbolic conception of mathematics, the ontological difficulties in this discussion do not arise at all.

\section{The end of the science of quantity}

The impact of the heritage from Euclid and the Aristotelian logical doctrine on modern mathematics is present not only in the modern logical tradition, but also in mainstream mathematics (e.g. mathematical analysis or Calculus) of the eighteenth and the

\footnotetext{
${ }^{22}$ Exceptions here are Poincaré's and the early Brouwer's critique of the foundational status of formal logic. But this critique has been largely ignored in the foundational discussion. Modern intuitionists and constructivists (with the exception perhaps of Errett Bishop) have their own formal logic with their own ontological notion of proposition.
} 
beginning of the nineteenth centuries. It seems to me that there is a deep tension at work between the two tendencies in mathematics during this time: on the one hand the Euclidean-Aristotelian heritage, with its ontological emphasis on geometry and 'continuous quantity', and the symbolic conception with its emphasis on the formal and operational aspect of mathematics, on the other. The latter tendency manifests itself in the 18th century in the effort to make algebra the foundation of mathematical analysis (Lagrange).

The former, ontological tendency was passed on by Newton, whose attitude to the tension between the two tendencies is somewhat puzzling. According to Guicciardini (2003: 75), Newton's interest in mathematics began in 1664, when he read, inter alia, François Viète's works, Descartes's Geometrie, Oughtred's Clavis mathematicae (1631) and Wallis's Arithmetica Infinitorum (1656). From reading these works on "modern analysis" Newton learned analytic geometry, algebra, tangent problems, and series, and he made his own contributions to this field of research that was highly symbolic. However, according to Guicciardini,

In the 1670s he was led to distance himself from this early highly analytical mathematical research. Newton began to criticize modern mathematicians. He stressed the mechanical character of modern algebraical methods $[. .$.$] By contrast, he characterized the "geometry$ of the Ancients" as simple, elegant, concise, adherent to the problem posed, and always interpretable in terms of existing objects. Needless to say, notwithstanding Newton's rhetorical declaration of continuity between his methods and the methods of the "Ancients", his geometrical dynamics is a wholly seventeenth-century affair. The reasons that induced this champion of analytics, series, infinitesimals, and algebra to spurn his analytical research are complex. They have to do with foundational worries about the nature of infinitesimal quantities [...]. They also have to do with his dislike of Descartes, towards anything Cartesian [...]. (Guicciardini 2003: 92)

Newton passed on the "methods of the Ancients", for instance, in the form of the ideas of absolute space, absolute time and absolute motion. Newton's assertion of these ideas resulted in a quite violent fight between Newton (via his spokesman Clarke) and Leibniz, who was a great symbolic thinker and argued for the 
relativity of place and motion. According to Hermann Weyl, "In this quarrel modern Physics sides entirely with Leibniz" (Weyl 2009: 125). We also recall that it was Leibniz', and not Newton's version of the infinitesimal calculus that survived into the 20th century. Leibniz' symbolic approach in mathematics and logic and its influence and success, is further support for the claim that the essence of modern mathematics is symbolic mathematics.

Many 18th century mathematicians conceived themselves to be concerned with a subject matter that belonged to geometry seen as the science of physical space or to physics as concerned with continuous quantities such as lengths, weights, area, volume, time, mass, power, speed, etc. As Epple points out, "During the 18th and part of the 19th century, many scientists still agreed with the idea that mathematics was the 'science of quantity' [...] It was selfevident to mathematicians of the 18th century that the quantities dealt with in analysis were endowed with meaning in the natural and social world" (Epple 2003: 291-2).

Many conceptual problems that were noted and discussed (but not solved) in 18th century mathematics had their source, it seems to me, in the deep tension between the mentioned two tendencies, i.e. between the view of numbers as quantities, and the symbolic view of numbers. There were problems about the nature of negative numbers: If numbers are quantities and 0 is nothing, how can there be quantities less than nothing? There were problems about infinitesimal magnitudes, differentials, the notion of limit, function, continuity, and one talked about the 'mysteries' of imaginary numbers. There were also problems concerning infinite divergent series. According to Jahnke "it was not self-evident that a formula obtained by algebraic expressions should be regarded as meaningless if it did not allow a numerical interpretation because a divergent series was involved" (Jahnke 2003: 108). This attitude to divergent series, that it should be possible (some day) to make sense of expressions and equations involving them, was according to Jahnke a typical attitude in 18th century analysis.

That Gauss felt a need for increased rigor in this situation, is clear from the following description he gives of the situation in mathematics: 
It is characteristic of mathematics of our modern times (contrary to antiquity) that our sign language gives us a lever that reduces the most complicated arguments to a certain mechanism. In this way science has gained infinitely in richness, but as the business is usually run, it has lost equally much in beauty and solidity. How often is this lever used only mechanically, although the authorization to do so in most cases implies certain tacit assumptions. I insist that by all applications of the calculus, by all applications of concepts one should remain conscious about the original conditions, and never without authorization consider the result of the mechanism as one's property. However, the usual trend is that one claims that analysis has a general character [...]. It is often like that in the case of divergent series. Series have a clear meaning when they converge; this clear meaning vanishes with this condition of convergence, and it changes nothing essential whether one uses the word sum or value. (Quoted in Lützen 2003: 173)

The image of mathematics as the science of quantity changes, however, profoundly in the late half of the 19th century. Epple writes about this change:

$[\ldots]$ one may reasonably call this change the end of the paradigm of the science of the quantity. Several parallel developments initiated the departure from this paradigm. In great Britain, a tradition of symbolical algebra emerged [...]. In the wake of other investigations (by Ernst Kummer, Hermann Grassmann, William Rowan Hamilton and many others), the notion of number was gradually extended far beyond its earlier limits. [...] By constructing new mathematical entities that could no longer be subsumed under the traditional notion of quantity, these developments exploded the extension of this concept. (Epple 2003: 291)

With the endeavor towards increased rigor in mathematics that begins with the work of Gauss, Cauchy, Weierstrass and others in the 19th century, the influence of the symbolic conception of mathematics is obvious and therewith also the endeavor towards a non-ontological outlook. Mathematical analysis was separated from geometry. Gaps were found in Euclid's arguments, and in addition, as a consequence of the invention of alternative geometries, Euclid's authority was questioned. It was felt that basic results in analysis (such as, for instance, the intermediate value theorem) should be given a firmer formal basis than being based on 
geometric intuition. Geometric intuition was also challenged by the invention (by Weierstrass and others) of functions that were continuous but nowhere differentiable.

In 18th century mathematics there was no sharp division between pure and applied mathematics. Most mathematicians also worked in theoretical physics. This fact reflected itself in the language of mathematics, in the prose of mathematics. Does a certain word such as, for instance, the word 'quantity' derive its meaning from its use in physics, or does it have its meaning from the way it is operated with in the mathematical calculus, i.e. does its mathematical sense coincide with its sense as a symbol of the calculus? It was only after the influence of the symbolic view of mathematics that this question could be raised, because an essential feature of the symbolic point of view was the logical separation of a symbolic system from its application to some subject-matter outside pure mathematics. This is why it is sometimes necessary to deprive words of their meaning in order to get clear about where the boundary between a symbolic mathematical system and its application goes. Even a word of ordinary language may have the role of a symbol in a calculus (such as, for instance, the words 'point' and 'line' in Hilbert's system in Grundlagen der Geometrie).

In Weierstrass' work on the arithmetization of analysis he is still using the word 'quantity', but it is clear that the sense of the word, as he is using it, is the sense it has as a symbol in the arithmetical calculus he is working with. Epple makes this point as follows: "Weierstrass continued to use the notion of quantity, but expressions like "arithmetical quantity" or "number quantity" made clear what he had in mind: a logical separation of his concepts from their more intuitive counterparts in geometry and physics" (Epple 2003: 296).

It is thus an important feature of the symbolic point of view to sharply separate a calculus or symbolic mathematical system, from its application to some independently given subject matter outside the system. This attitude towards the relation between pure and applied mathematics was in keeping with a more general tendency in 19th century mathematics, which Lützen describes as the existence of "A process of emancipation of mathematics from 
science" and this process "added to the feeling that the foundations of analysis had to be revised. [...] It became important to give mathematics, including analysis, a solid foundation of its own, independent of applications" (Lützen 2003: 155-6).

It is interesting that one important motivation for the rigorization of analysis, was problems concerning the teaching of mathematics. According to Lützen, "Several mathematicians found themselves in an awkward situation when they had to teach the introduction to analysis, and therefore they decided to reform it" (Lützen 2003: 155). Lützen argues that this was the direct background for Cauchy's and Weierstrass's reforms and of Dedekind's and Méray's construction of the real numbers. It seemed most natural from a pedagogical point of view to introduce basic notions of analysis, such as the notion of infinitesimal magnitude, through their applications in physics. The 'awkward situation' was the impression that the correctness of the basic concepts of pure mathematics seemed to depend on their successful applications in physics - as if pure mathematics was at bottom not really pure.

The process of "emancipation of mathematics from science" did manifest itself in the organization of higher education in mathematics in Germany in the 19th century. Lützen explains: "[...] high schools and universities rather than technical high schools became the centres of mathematical training and research. Combined with the neo-humanist movement, this led to the development of pure mathematics as an independent field" (Lützen 2003: 155$)^{23}$

In Cauchy's work on reforming analysis in his Cours d'analyse it is clear that the symbolic point of view is present in an essential way. This is true in particular in Chapter VII where he introduces imaginary numbers. According to Bottazzini, "Cauchy took the ontological problem concerning the nature of imaginary numbers much more seriously than anyone before him. In the Cours d'analyse

\footnotetext{
${ }^{23}$ It seems clear to me that it was the symbolic point of view, with its algebraic methods and techniques, that made this development of mathematics into an independent field possible. This development can, for this reason, be said to support the claim that "modern mathematics is symbolic mathematics".
} 
he introduced them in a formal manner as "symbolic expressions" given by "any combination of algebraic signs that do not signify anything in themselves or to which one attributes a value different from that which it naturally has" (Bottazzini 2003: 217). Cauchy does not solve the "ontological problem" about imaginary numbers by giving a positive answer to the question of their "ontological nature", but by making the ontological problem disappear in the light of a rigorous symbolic approach to the nature of imaginary numbers. And Cauchy's approach required hard work. Bottazzini reports that "it took him no less than fifty-five pages to $[. .$.$] define$ algebraic operations on 'expressions' like $\alpha+\beta \sqrt{-1}(\alpha$ and $\beta$ being real quantities) in a rigorous way and to establish their properties." In Bottazzini's judgement, "Chapter VII of the Cours can be considered one of the places where Cauchy displayed his concept of rigor best."

The symbolic algebra that was developed by George Peacock (1791-1858) and Augustus de Morgan (1806-1871) was, in a sense, an expanded symbolic approach. The algebraic symbolism was not just an arithmetic-algebraic symbolism. The symbols of algebra were no longer understood as representing necessarily numbers or magnitudes. In the chapter headed "On symbolic algebra" in de Morgan's book Trigonometry and Double Algebra (1849), he writes:

It is most important that the student should bear in mind that, with one exception, no word or sign of arithmetic or algebra has one atom of meaning throughout this chapter, the object of which is symbols, and their laws of combination, giving a symbolic algebra which may hereafter become the grammar of a hundred distinct significant algebras. If any one were to assert that + and - might mean reward and punishment, and $A, B, C$, etc., might stand for virtues and vices, the reader might believe him, or contradict him, as he pleases, but not out of this chapter. The one exception above noted, which has some share of meaning, is the sign $=$ placed between two symbols as in $A=$ $B$. It indicates that the two symbols have the same resulting meaning, by whatever steps attained. That $A$ and $B$, if quantities, are the same amount of quantity; that if operations, they are of the same effect, etc.

This is reminiscent of what Hilbert wrote to Frege in the so-called Frege-Hilbert controversy: 
[1] $\mathrm{t}$ is surely obvious that every theory is only a scaffolding or schema of concepts together with their necessary relations to one another, and that the basic elements can be thought of in any way one likes. If in speaking of my points I think of some system of things, e.g. the system: love, law, chimney-sweep [...] and then assume all my axioms as relations between these things, than my propositions, e.g. Pythagoras' theorem, are also valid for these things. In other words: any theory can always be applied to infinitely many systems of basic elements. $^{24}$

The system of symbolic algebra of de Morgan is not a theory about anything external to the system. It is a self-standing mathematical symbolism that can be applied to other independently existing subject matters.

One of the most clear and distinct examples of the use of the symbolic point of view is the mathematician Johannes Thomae's concept of "formal arithmetic" presented in the introduction of the second edition to his book Elementare Theorie der analytischen Functionen einer complexen Veränderlichen, published in 1898. As Thomae uses the word 'formal' it is essentially synonymous with 'symbolic', as this word has been used in mathematics ever since Vieta.

What makes Thomae's clarification of formal or symbolic arithmetic exceptional is his use of the game of chess comparison in order to make clear the relevant notion of 'form' in formal arithmetic. With the game comparison he brings in the aspect of mathematics as activity, as operational practices (in opposition to mathematics as doctrines, laws, disciplines, theories), which is so important in the symbolic point of view. Thomae summarized his standpoint as follows:

The formal conception of numbers sets itself more modest limitations than does the logical conception. It does not ask, what are and what shall the numbers be, but it asks, what does one need about numbers in arithmetic. For the formal conception, arithmetic is a game with signs which one may call empty; by this one wants to say that (in the game of calculation) they have no other content than that which has been attributed to them concerning their behaviour with respect to

\footnotetext{
${ }^{24}$ Letter to Frege of December 29, 1899, as excerpted by Frege in Frege $(1980,40)$.
} 
certain rules of combination (rules of the game). Similarly, a chess player uses his pieces, he attributes to them certain properties which condition their behaviour in the game, and the pieces themselves are only external signs for this behaviour. To be sure, there is an important difference between the game of chess and arithmetic. The rules of chess are arbitrary, the system of rules for arithmetic is such that by means of simple axioms the numbers can be related to intuitive manifolds, so that they are of essential service in the knowledge of nature. - The formal standpoint relieves us of all metaphysical difficulties, this is the benefit it offers us. (Quoted from Epple 2003: 301)

Thomae here begins by dissociating himself from the questions of the ontological nature of numbers on the grounds that answers to these questions are not needed in arithmetic. The ontological issues arise in discussions of the logical or philosophical foundation of arithmetic, but not in arithmetic as a mathematical practice. And don't we have to agree with Thomae here? What would be an example of a mathematical problem in arithmetic, be it in elementary arithmetic or in advanced research arithmetic, for which the ontological nature of numbers (as discussed by philosophers) would make a difference?

In arithmetic, seen as a game with signs, the signs are said to be, in one sense, empty of content. But in another sense they do have content. They don't have a content in the game that comes from explanations or translations given in mathematical prose (using the words 'quantity' and 'magnitude'). The arithmetical calculus, like the game of chess, is autonomous. But the signs do have content in the calculus, namely the 'content' attributed to them concerning their function and behavior with respect to the rules of the calculus. It is this content that constitutes the forms of formal (or symbolic) arithmetic. These forms are not features of the signs as objects of visual perception, they are rather forms of the use of signs.

The words 'sign' and 'symbol' are often used as synonymous words. But here it is important to distinguish between a symbol as a form of use of a sign, and the 'sign' as the external and immediately perceivable mark for this form of use. The difference becomes clear in the game of chess comparison. By a chess piece we may mean a certain immediately perceivable visual object with a 
certain color, shape and size that distinguishes it from other pieces in the game, but we also talk about a chess piece as an object with properties that condition its behavior in the game, i.e. as a piece with which you can make certain moves in the game but not others. The word 'formal' in Thomae's "formal arithmetic" refers to the behavior of arithmetical 'chess-pieces' in the latter sense.

Thomae was not the only mathematician who used the word 'formal' in this way around the end of the 19th century. This raises of course the question if the symbolic view of mathematics coincides with formalism. It is difficult to give a short answer to this question since the word 'formalism' has often been used in a superficial, pejorative sense (e.g. by Brouwer and Frege), sometimes even as a caricature of the symbolic view of arithmetic, such as, for instance, when it is said that a formalist considers arithmetic or geometry "as games with empty signs". Note that Thomae hesitates in the quotation above about using the word 'empty'. The symbols of his formal arithmetic are not empty; they have a content determined by the forms of their use - not by possible applications of the system, or by semantical explanations.

The mathematician Hermann Grassmann uses the words 'form' and 'formal' in a way similar to Thomae's in Grassman's book Die lineale Ausdehnungslehehre, published in 1844. The book begins with an introduction in which Grassmann gives an account of his conception of mathematics. He disassociates himself from the ontological conception of logic and mathematics by making a basic division of sciences in real (Reale) and formal (Formale): Thinking in the real sciences always takes place with respect to an independently existing subject matter outside thinking. In mathematics, being a formal science, the subject matter of thinking is posited by thinking itself and in a second act of thought it is made the object of study of mathematics as a formal science. The object of study of pure mathematics is forms of thought (Denkformen). Pure mathematics is Formenlehere (doctrine of forms), says Grassmann. Now, if thinking is linguistic in nature (which was also a common idea by this time); if thinking is operating with signs 
(including pictures and figures), this would mean that the Denkformen of pure mathematics are forms of the use of signs. ${ }^{25}$

Hilbert comes close to Grassmann's idea when he says about the 'formula game' of his proof theory:

This formula game is carried out according to certain definite rules, in which the tecbnique of our thinking is expressed. These rules form a closed system that can be discovered and definitively stated. The fundamental idea of my proof theory is none other than to describe the activity of our understanding, to make a protocol of the rules according to which our thinking actually proceeds. (Hilbert 1927: 475)

A very pertinent formulation of the symbolic view of mathematics was given by the French mathematician and philosopher Luis Couturat, in his book De l'infini mathématique (1896). Like Thomae, Couturat also uses he game of chess comparison:

\footnotetext{
${ }^{25}$ With his "Ausdehnungslehre" (or extensive, or geometric algebra) Grassmann initiated a new research orientation in modern symbolic mathematics, which would get many applications in theoretical physics. The following historical account comes from the Wikipedia article, "Geometric Algebra": "GA [geometric algebra] in the sense used in this article was not developed until 1844, when it was used in a systematic way to describe the geometrical properties and transformations of a space. In that year, Hermann Grassmann introduced the idea of a geometrical algebra in full generality as a certain calculus (analogous to the propositional calculus) that encoded all of the geometrical information of a space. Grassmann's algebraic system could be applied to a number of different kinds of spaces, the chief among them being Euclidean space, affine space, and projective space. Following Grassmann, in 1878 William Kingdon Clifford examined Grassmann's algebraic system alongside the quaternions of William Rowan Hamilton. From his point of view, the quaternions described certain transformations (which he called rotors), whereas Grassmann's algebra described certain properties (or Strecken such as length, area, and volume). His contribution was to define a new product - the geometric product - on an existing Grassmann algebra, which realized the quaternions as living within that algebra. Subsequently Rudolf Lipschitz in 1886 generalized Clifford's interpretation of the quaternions and applied them to the geometry of rotations in $\mathrm{n}$ dimensions. Later these developments would lead other 20th-century mathematicians to formalize and explore the properties of the Clifford algebra. [...] Progress on the study of Clifford algebras quietly advanced through the twentieth century, although largely due to the work of abstract algebraists such as Hermann Weyl [Brauer and Weyl (1935)] and Claude Chevalley. [...] In physics, geometric algebras have been revived as a "new" way to do classical mechanics and electromagnetism, together with more advanced topics such as quantum mechanics and gauge theory. David Hestenes [Hestenes, and Sobczyk, (1984)] reinterpreted the Pauli and Dirac matrices as vectors in ordinary space and space-time, respectively, and has been a primary contemporary advocate for the use of geometric algebra." <https:// en.wikipedia.org/wiki/Geometric_algebra\#History> (Accessed July 8, 2015.)
} 
A mathematician never defines magnitudes [or numbers] in themselves, as a philosopher would be tempted to do; he defines their equality, their sum and their product, and these definitions determine, or rather constitute, all the mathematical properties of magnitudes. In a yet more abstract and more formal manner he lays down symbols and at the same time prescribes the rules according to which they must be combined; these rules suffice to characterize these symbols and to give them a mathematical value. Briefly, he creates mathematical entities by means of arbitrary conventions, in the same way that the several chessmen are defined by the conventions which govern their moves and the relations between them. (Quoted in Bell 1937: 624)

If formalism is a concern with form, and form is understood as in Thomae, Grassman, Couturat as forms of use of signs, as relating to the function and behavior of signs in a calculus, then clearly formalism is closely related to the symbolic view of mathematics. But in the philosophical discussion about formalism in the 20th century (a discussion which has been dominated by mathematical logic in its foundational status), formalism tends to be understood against the background of the ontological view in which mathematical propositions are taken to have a descriptive content a mathematical system or theory is seen as a body of truth, or a body of knowledge about some independently existing subject matter. In this picture the aspect of mathematics as human activity, as operational practices, tends to disappear, and so does also the notion of a symbol as something else than a sign. A mathematical symbolism is often misunderstood as a system of notation with a naturalistic conception of signs and expressions. As a result, formalism becomes a kind of caricature of the symbolic view. It is 'formalism' in that pejorative sense that Frege is attacking when he says:

In order to produce it [an infinite series] we would need an infinitely long blackboard, an infinite supply of chalk, and an infinite length of time. We may be censured as too cruel for trying to crush so high a flight of the spirit by such a homely objection; but this is no answer. (Frege 1960: 219)

Heine and Thomae made some less successful remarks that might seem to invite this objection. But it is doubtful if anyone has seriously held a formalist view of mathematics that would make 
this remark into a fair objection. In Frege's critique of the formalists, it is clear that he had an ontological conception of arithmetic that he never questions (Frege 1960: 182-233). He emphasizes arithmetic as a science (rather than as an activity or practice), and the subject matter of this science is the abstract objects that are the 'reference' of the number signs. It is, for Frege, on the basis of our knowledge of the sense and reference of the number signs that the rules of arithmetic are justified. Wittgenstein's remark about Frege's critique of the formalists quoted in section 5 seems to me very much to the point.

There is also a notion of formalism that has been called "Hilbert's formalism", but this "formalism" is rather an unfair polemic picture of Hilbert's views for which Brouwer was originally responsible. According to Georg Kreisel, "We note at once that there is no evidence in Hilbert's writings of the kind of formalist view suggested by Brouwer when he called Hilbert's approach "formalism" (Kreisel 1958: 346). This is to some extent an exaggeration. Hilbert never called himself a formalist, but some of his statements show that he was no doubt influenced by what was called the "formal approach" around the turn of the century. But Kreisel is certainly right in saying that the notion of "Hilbert's formalism" is to a great extent a fabrication of Brouwer's. It is not a very clear notion since Brouwer tends to put every view of mathematics that he dislikes or rejects under the label "formalism". A more interesting view of Hilbert's foundational work is given by Hermann Weil when he suggests a reading of Hilbert's prooftheoretical program with its "formula game" as being a symbolic construction (Weyl 1927: 136-41).

Frege's and Brouwer's critique of formalism manifests a blindness towards the symbolic aspect of mathematics. This blindness is reinforced in the 1930's through the notion of 'logical syntax' and the sharp division between syntax and semantics attached to it, which has become generally accepted and very influential in the literature of logic and analytic philosophy since the 1930's. The crucial feature of syntax in this sense (not to be confused with what Wittgenstein called 'logical syntax' in the Tractatus) is its naturalistic conception of language. The instigators 
of this syntax terminology, Carnap, Gödel and Tarski, were very explicit about its naturalistic character. As already mentioned, Carnap said that "syntax, pure and descriptive, is nothing more than the mathematics and physics of language" (Carnap 1959: 284). This approach to language, in particular to the language of mathematics, blocks the aspect of language that the game of chess comparison opens up, such as for instance the difference between sign and symbol. That mathematics is at bottom activity, operational practices, forms of use of signs disappears as something inessential.

Syntax, with the associated division between syntax and semantics, has of course been successful and influential for the invention of new mathematical theories of formal systems (where the words 'form' and 'formal' have the specific syntactical sense), theory of automata, applications in computer science, etc., but it is doubtful if this development has contributed to increased rigor of ordinary mathematics. Hasn't logical semantics, including logical model theory, on the contrary cemented the old ontological view of mathematics?

Let me finally mention one prominent mathematician who explicitly called his own conception of mathematics formalism, in a sense that comes close to the symbolic conception of mathematics. It is Felix Hausdorff, who was working in set theory and is considered as one of the founders of topology. His book Grundrüge der Mengenlehre, published in 1914 is often described as a groundbreaking work in modern mathematics. But in the first decade of the 20th century Hausdorff expressed (in manuscripts he never published) a view of set theory as a symbolic system without any ontology. It was a view in sharp contrast to Cantor's philosophical understanding of set theory. Hausdorff's work falls within the rigorization movement around the beginning of the 20th century. We will return to Hausdorff in the next section.

The main point of this section has been to argue that an increased awareness and use of the symbolic conception of 
mathematics, was one essential part of the rigorization of mathematics in the late 19 th century. ${ }^{26}$

\section{Wittgenstein on calculus and mathematical 'prose'}

There are many examples of the prose/calculus distinction in the strict symbolic point of view that Wittgenstein held, at least in the middle period (cf. Stenlund 2012), when he spoke of mathematics as consisting of symbolic systems, games or calculi that are autonomous systems determined by rules for the operation and transformation of expressions. Again and again he warned about what he called the prose accompanying the calculus (the verbal readings in ordinary language of the signs and expressions of the calculus) especially when this prose does not derive from some application of the calculus to something outside mathematics (PG, 324).

If proximity to ordinary language was an essential feature of ancient Greek mathematics, Wittgenstein's strict symbolic view of modern mathematics is diametrically opposed to this feature. His attitude seems to have been that modern mathematics, despite great progress in the last two centuries, has not yet found its true individuality or authenticity, but is still holding on to antiquated features of the Euclidian-Aristotelian tradition.

He saw, in fact, prose accompanying the calculus as the main source of puzzles and confusion in the discussion of the foundations of modern mathematics. The following quotation from Philosophical Grammar is one of many passages where he makes this point:

If you want to know what the expression "continuity of a function" means, look at the proof of continuity [of functions]; that will show what it proves. Don't look at the result as it is expressed in prose, or in the Russellian notation, which is simply a translation of the prose expression; but fix your attention on the calculation actually going on in the proof. The verbal expression of the allegedly proved proposition is in most cases misleading, because it conceals the real purport of the proof, which can be seen with full clarity only in the proof itself. (PG, 369-70)

${ }^{26}$ More examples in support of this claim can be found in Epple (2003). 
By the 'Russelian notation' he means the mathematical logic of Principia Mathematica, in which a formula such as $(\exists x) f x$ is translated and explained as the verbal sentence "There exists an object $x$ which has the property $f$ ', which we do understand as an English sentence (or a form of English sentences). But this is a very vague sense of understanding, since it is based only on the doctrine of sentence construction of English, and that doctrine says nothing, or very little, about the use of the sentence and the contexts of its use. Does it mean the same when the variable $x$ ranges over a finite domain, as when any number can be a value of the variable? Through mathematical logic any proposition can be represented in the mathematical notation of modern logic, "and this makes us feel obliged to understand it. Although of course this method of writing is nothing but the translation of vague ordinary prose" (RFM, 299). So one important example of 'prose accompanying the calculus' is the ordinary language expressions used in the translation of the signs and formulas of the predicate calculus into verbal language.

In his Notebooks Wittgenstein said that "My whole task consists in explaining the nature of the proposition" (NB, p. 39). But it was clear to Wittgenstein from the start that the propositions explained in the Tractatus do not include mathematical propositions. The propositions of the Tractatus express possible states of affairs about objects that are the substance of the world, but the statements of mathematics in the Tractatus do not express possible states of affairs about independently existing objects of a mathematical realm. A symbolic conception of arithmetic is present already in the Tractatus. The opposite view in which mathematical and nonmathematical propositions are propositions in the same sense (which is the more or less established view in the branch 'mathematical logic and the foundations of mathematics') is based on the similarities in the readings in "vague ordinary prose" of mathematical and non-mathematical statements.

If persuasion was ranked above precision in Greek mathematics, it is clear that Wittgenstein wanted to reverse this ranking, provided that 'precision' means conceptual precision. This precision is not achieved by merely changing notation, i.e. using mathematical notation that is translated into "vague ordinary 
prose". Such a change may result rather in a deceitful feeling of persuasiveness about an achieved precision.

One difficulty with understanding the last quoted passage is Wittgenstein's use of the word 'proof. Many of Wittgenstein's examples of proofs in RFM are really only calculations, while the established use of the word 'proof among philosophers, logicians as well as professional mathematicians is still following the Aristotelian-Euclidian tradition, and then a proof tends to be contrasted with a calculation. (Poincaré calls calculation 'verification' and contrasts verification with proof.) A proof in the Euclidian sense is essentially expressed in verbal language, in mathematical prose. It consists of a sequence or a pattern of propositions, related to one another by rules of inference. This conception of a proof was questioned in the Tractatus on the basis of the distinction between saying and showing, which was one of Wittgenstein's tools in the Tractatus for clarifying the logical structure of language in general from a more strict symbolic point of view in which the notions of form and operation are essential. A form as Wittgenstein uses this word (even in his later philosophy), cannot be described: it can only be presented (PR, p. 208). A form is not a property of a substrate. So there is a problem here, for instance, with the form of 'actually infinite sets'. How can there be actually infinite sets if their form cannot be presented? They must presuppose an "underlying imaginary symbolism" (PG, 470). The idea of mathematical entities outside any symbolism was incomprehensible to Wittgenstein's symbolic view of mathematics. It would perhaps be comparable to the idea of (partly) human-like beings, having no bodies, like spirits or angles.

It was a fundamental idea about arithmetic in the Tractatus that the logical forms of the propositions of language have an arithmetical structure. The logical forms are formal or internal properties and relations that show themselves in the symbolism, in how they are generated by the operations in the universal calculus of propositions in the Tractatus.

The concept of an operation and a series generated by successive applications of an operation is the basis for the Tractatus' 
conception of arithmetic. A number is explained as a specific kind of symbol, namely as an exponent of an operation (TLP 6.021).

In the change that takes place in Wittgenstein's thinking in the 1920's, the universal calculus of the Tractatus loses its privileged position, and becomes one calculus among many others. But what does not change is his interest in mathematics as methods and techniques for operating with and transforming expressions and symbols. It is against this background that Wittgenstein prefers to talk about a mathematical system as a calculus, rather than as a theory about something, or a deductive system of propositions having descriptive contents.

So when Wittgenstein is questioning the use of prose in mathematics as being a source of confusion, he is questioning the (non-symbolic) conception of proposition and proof with roots in the Aristotelian-Euclidian tradition. Many of the verbal expressions that belong to the prose accompanying the calculus have their origin in philosophy, not least in the Aristotelian-Euclidean tradition.

In the following remark Wittgenstein suggests a method for separating calculus and (inessential) prose:

In set theory what is calculus ought to be separated from what claims to be (and of course it cannot be) theory. The rules of the game have thus to be separated from inessential statements about the chessmen.

Frege replaced those signs in Cantor's alleged definitions of "greater", "smaller", "+", “-", etc., with new words, to show that here there wasn't any real definition. In the same way, in all of mathematics one could replace the usual words, especially the word "infinite" and its cognates, with entirely new and hitherto meaningless expressions, in order to see what the calculus with these signs really achieves and what it doesn't achieve. If the idea was widespread that chess gave us information about kings and castles, I would propose to give the pieces new shapes and different names, so as to demonstrate that everything belonging to chess has to be contained in the rules. (PG, 468-9)

What such an investigation of the word "infinite" would reveal, for instance, is that there is often a confusion of the mathematical sense of 'infinite' and the use of the word 'infinite' as a superlative 
for something finite that strikes us as enormously large, as when we say "The number of trees along the road looks infinite", or "The number of stars in the sky is infinite". And then we are in danger of accepting the picture of an infinite sequence in mathematics as if it were an extremely long finite sequence, as if an infinite sequence in mathematics has an end, but one that it is 'infinitely far away'. But the expression 'infinitely far away' is not a measure of a distance or length, it is a superlative we use about extremely large finite distances. That sense of 'infinite' does not achieve anything in the calculus of set theory.

The separation of calculus and prose is an important part of Wittgenstein's conceptual (or grammatical) investigation. And it is a difficult part since we do not survey and are not aware of the ways in which the use of 'prose-expressions' in a mathematical system affects our understanding of the system as a whole.

In the late half of the $19^{\text {th }}$ century it became more and more obvious that the formal deductive structure in Euclid's elements was not really 'formal'. Many arguments did depend on the prose meaning of words (such as for instance the word 'between'). It was clear that the 'formal deductive' style in Euclid also had a tacit rhetorical purpose.

This is what Hilbert's axiomatization of geometry tried to correct. But Hilbert still followed the tradition in viewing pure geometry as a theory about something (about some 'unspecified things', as he expressed it), and he was led to the idea of the axioms as propositions defining the notions involved. Einstein saw the possibility of viewing geometry as a pure calculus, an autonomous system (in which the axioms are rules for the operation with signs and figures), and which, as a pure calculus, is not 'about anything outside the calculus', but which can be applied to things in nature, for instance, in the description of physical space. ${ }^{27}$

One of the first mathematicians who clearly expressed the view of geometry as an autonomous system, independent of intuition or any empirical basis, was Felix Hausdorff. In a manuscript with the

\footnotetext{
${ }^{27}$ Einstein's theory of relativity was no doubt a source of inspiration for Wittgenstein in the middle period (RFM VI, $\ 28$ ). See also Stenlund 2012: 149-152.
} 
title Formalism from around 1904, he says about mathematics, and geometry in particular, that "The most important and fundamental task of modern mathematics has been to set itself free from this dependency [on intuition and empirical bases], to fight its way through from heteronomy to autonomy" (quoted in Corry 2006: 148). Leo Corry summarizes Hausdorff's view as follows:

This autonomy, so fundamental for the new view of mathematics predicated by Hausdorff and widely adopted later on as a central image of twentieth century mathematics, was to be attained precisely by relying on the new conception of axiomatic systems embodied in GdG [Hilbert's Grundlagen der Geometrie]. [...] Pure mathematics, under this view, is a 'free' and 'autonomous' discipline of symbols with no determined meaning. Once a specific meaning is accorded to them, we obtain 'applied' mathematics. Intuition plays a very important heuristic and pedagogical role, but it is inexact, limited, misleading and changing, exactly the opposite of mathematics. (Corry 2006: 148-9) ${ }^{28}$

In the beginning of the 1930's Wittgenstein was, no doubt, influenced by this modernistic "central image of twentieth-century mathematics". The "inexact, limited, misleading, and changing" intuition mentioned here comes to expression in what Wittgenstein calls 'prose'.

That being said, there is also a philosophically important difference between a professional mathematicians' attitude (such as Hausdorff's) to the new axiomatic method and Wittgenstein's. Wittgenstein never saw it as his concern to express opinions about the final or ideal shape of geometry and arithmetic as disciplines of the science of mathematics, which was a natural concern for a professional mathematician for whom mathematics is research mathematics and higher mathematical education (while the rest is 'trivial mathematics'). For Wittgenstein, elementary mathematics, seen as established practices, methods and techniques of a wider circle of mathematical agents than the circle of professional mathematicians, is the rock bottom of mathematics. This is also a

\footnotetext{
${ }^{28}$ It is interesting that Hilbert was less inclined to view his Grundlagen der Geometrie as the paradigm for a formalistic view of mathematics, of geometry in particular, than Einstein and Hausdorff and many others. As Corry makes clear, Hilbert often questioned the autonomy of geometry and claimed that geometric knowledge has an empirical basis.
} 
reason why the word 'calculus' is more appropriate than the word 'discipline' for Wittgenstein.

This difference reflects Wittgenstein's attitude to the idea of "the foundations of mathematics". The foundations that are Wittgenstein's concern are already there in the established mathematical activities and practices and the task is to get clear about it - and that reflection over elementary mathematical practice is not a mathematical task. The task is not to invent a foundation for mathematics through mathematical construction (such as Principia Mathematica or axiomatic set theory), or to propose a mathematical research program (such as the intuitionistic constructivization of mathematics or Hilbert's proof-theory). The roots of the worries about the foundations of mathematics are according to Wittgenstein our lack of a clear view of the workings of the mathematical symbolism (caused partly by the role of prose in mathematics). And this lack of a clear view manifests itself in the problems, or puzzles (as he calls them) he is concerned with in his writings and lectures on the foundations of mathematics. This is one reason why Wittgenstein's style of writing about the foundations of mathematics is so different from the normal styles of writing in this branch. In order to accentuate that he is not doing 'foundations of mathematics' in the mathematician's sense, he points out in the first lecture of the series of lectures he gave on the foundations of mathematics in Cambridge in 1939 that "I am going to talk about the interpretation of mathematical symbols, but I will not give a new interpretation." With regard to the puzzles he will deal with, he says that "all the puzzles I will discuss can be exemplified by the most elementary mathematics" (Diamond (ed.) 1976: 13-4).

Wittgenstein is very clear about his attitude to the foundations of mathematics in the following remarks:

What does mathematics need a foundation for? It no more needs one, I believe, than propositions about physical objects - or about sense impressions, need an analysis. What mathematical propositions stand in need of is a clarification of their grammar, just as do those other propositions. 
The mathematical problems of what is called foundations are no more the foundation of mathematics for us than the painted rock is the support of a painted tower. (RFM, 378)

This remark, and similar critical remarks about mathematical logic and the foundations of mathematics, may make it look as though Wittgenstein's philosophy of mathematics is exclusively critical and negative. But the positive message is Wittgenstein's symbolic conception of mathematics that he did not launch as a new branch of the foundations of mathematics, since it already existed within mathematics since many centuries and only needed to be clarified. The symbolic view is an important feature of the most progressive development of the mathematics created in the last three centuries up to and including the mathematics of quantum physics (as I shall argue in the last section). But it needs to be made clear since it is obscured by various other trends - such as mathematical logic in its foundational status. Wittgenstein could not help seeing that in the light of his symbolic conception, mathematical logic in that role stands out as a remnant from an antiquated ontological conception of mathematics of the past. ${ }^{29}$

Wittgenstein tended, however, to exaggerate the calculus/prose distinction in the beginning of the thirties, when he was inclined to see mathematics as pure calculus. ${ }^{30}$ Maybe this exaggeration was an effect of how Wittgenstein was influenced by what Corry called "a central image of twentieth century mathematics" in the quotation given before. In any case, there is a change on this point in Wittgenstein's thinking in the middle of the 30's when a more anthropological point of view enters in connection with his work on rule following and as a result of criticism by Piero Sraffa. Wittgenstein realized that mathematics is not a sharply delimited field. The use of mathematical signs in applications outside

\footnotetext{
${ }^{29}$ Wittgenstein says (RFM, 300), "'Mathematical logic' has completely deformed the thinking of mathematicians and of philosophers, by setting up a superficial interpretation of the forms of our everyday language as an analysis of the structures of facts. Of course in this it has only continued to build on the Aristotelian logic."

${ }^{30}$ In a remark written in the beginning of the 30 's, he says: "Mathematics consists entirely of calculations. In mathematics everything is algorithm, and nothing is meaning, even when it doesn't look like that because we seem to be using words to talk about mathematical things. Even these words are used to construct an algorithm" (PG, 468).
} 
mathematics contributes to the meaning of mathematical signs. ${ }^{31}$ But the calculus/prose distinction is still important in his later work, though in a less dogmatic sense. Similarities between statements in prose or in verbal language are still in many cases the source of false or misleading analogies.

Let us look at one of Wittgenstein's examples that shows how prose, or verbal language, may mislead us into (or may seem to justify) a belief in an ontological realm of mathematical objects, having independent existence. Consider the two sentences

A human being has two eyes

and

A quadratic equation has two roots ${ }^{32}$.

Due to the similarity in the verbal form of the two statements, it may be tempting so say: as the first proposition is about objects outside mathematics (eyes of a human being), so the second is about independently existing mathematical objects (numbers that are roots of a quadratic equation). And we would be led to an ontological realm of numbers.

However, looking at the concept of the roots of equations we see that numbers that are roots of quadratic equations do not exist independently of mathematics, but only in the context of the arithmetical-algebraic symbolism. The roots of an algebraic equation of the form $x^{2}+a x+b=0$ are given by two different algebraic expressions. (This holds despite the fact that any equation of the form $(x-a)^{2}=0$, with $a>0$ has, in a sense, only one root, but as the concept of the roots of a quadratic equation is determined in the algebraic symbolism, this means that the two roots of these quadratic equations happen to coincide.)

It is the similarity in the verbal form of the statements of number outside and inside mathematics that makes it appear as though they were results of "applying mathematics" in the same sense. That is the false analogy. The decisive thing is that it is only

\footnotetext{
${ }^{31}$ In RFM (p. 257, written in 1942) he says: "It is the use outside mathematics, and so the meaning of the signs, that makes the sign-game into mathematics."

32 Wittgenstein discusses a similar example in Diamond (ed.) 1976: 150.
} 
the application of arithmetic to something independently given outside mathematics (such as eyes of people) that deserves to be called applied mathematics, and which is opposed to pure mathematics. The statement "A quadratic equation has two roots" is a statement of pure mathematics that is based on an algebraic proof, and not on counting objects in some realm outside the arithmetical-algebraic symbolism.

\section{Leibniz on blind thought and Hilbert's ignorance of the use of signs}

There is a similarity between Wittgenstein and Leibniz, concerning the difference between calculus and prose. Recall the quotation above in which Wittgenstein says:

In set theory what is calculus ought to be separated from what claims to be (and of course it cannot be) theory. The rules of the game have thus to be separated from inessential statements about the chessmen.

He continues by suggesting a method for making the separation between the role of the word 'infinite' as a piece in the game or calculus of set theory, and its role as a prose expression with a 'linguistic meaning' of its own in statements about the 'chesspieces', statements that purport to refer to something independently existing beyond the calculus, something that set theory is taken to be a 'theory about'. ${ }^{33}$

\footnotetext{
${ }^{33}$ The prose meaning of 'infinite' often invites a (false) analogy between an infinite sequence and an extremely large finite sequence - as if an extremely long sequence of numbers of the form $1,2,3, \ldots, \mathrm{n}$ is 'closer to' or 'more similar to' the sequence of all natural numbers than a short finite sequence of this form. It is on the basis of this analogy that it seems to make sense to conceive of the set of natural numbers as an extension (in which the generation of numbers by iteration of the successor operation "has been completed", i.e. carried out to the end which the sequence of naturel numbers does not have!). It seems to me that the normal meaning (for most logicians) of a proposition beginning with a universal quantifier which ranges over the set of natural numbers $\mathrm{N}$, is to think of $\mathrm{N}$ as an extension.

The mathematician Niels Henrik Abel was very dissatisfied with the theory of infinite series of his times. He complained that "One applies all operations to infinite series as though they were finite, but is that permissible? Hardly. - Where is it proved that one gets the differential of an infinite series by differentiating each term?" (Quoted in Lützen 2003: 177).
} 
Leibniz was concerned with a similar problem with his infinitesimal calculus when he was criticized for not making clear what the infinitesimal calculus 'is about'. By not distinguishing calculus and mathematical prose the critics were misled by the prose into seeing the infinitesimal calculus as a theory about something, such as infinitesimal magnitudes. Leibniz reacted to criticisms of the differential calculus for having an unclear foundation, and for the uncertain status and nature of the infinite and the infinitesimals by saying that "it is unnecessary to make mathematical analysis depend on metaphysical controversies or to make sure that there are lines in nature which are infinitely small in a rigorous sense in contrast to our ordinary lines, or as a result, that there are lines infinitely greater than our ordinary ones, yet with ends" (Loemker 1969: 542-3). As Krämer points out (1996: 85): "Leibniz emphasized that the inner coherence of his calculus does not depend on the metaphysical dispute how to interpret the differential symbolism. To calculate correctly does not presuppose an answer to the question of whether an infinitesimal magnitude exists as an actual or as a potential infinity." Herman Weyl makes a similar point: "many of the Leibnizian statements sound as if his view of the infinitely small is that it [...] cannot be given a reasonable contentual interpretation, yet that nonetheless all things stand as if it [the infinitely small] did actually exist. All that matters for the mathematicians is that it fits into the calculus of signs without contradiction" (Weyl 1927: 139). ${ }^{34}$

One of Leibniz' great achievements was his clarification of the notion of calculus on the basis of the distinction he made between two kinds of thinking: symbolic or blind thought on the one hand, and intuitive thought on the other. 'Intuitive thoughts' are what Leibniz often refers to as ideas. Starting out from limitations of human mental capacities, he explains the distinction as follows:

...especially in longer analysis, we do not intuit the entire nature of the subject matter at once but make use of signs instead of things [...]. Thus when I think of a chiliogon, or a polygon of a thousand equal sides, I do not always consider the nature of a side and of equality and

${ }^{34}$ Ishiguro (1990: Ch V), gives a very penetrating account of Leibniz's notion of the infinitesimal. 
of a thousand (or the cube of ten), but I use these words, whose meaning appears obscurely and imperfectly to the mind, in place of ideas which I have of them, because I remember that I know the meaning of the words but that their interpretation is not necessary for the present judgment. Such thinking I usually call blind or symbolic, we use it in algebra and in arithmetic, and indeed almost everywhere. When a concept is very complex, we certainly cannot think simultaneously of all the concepts which compose it. But when this is possible, or at least insofar as it is possible, I call the knowledge intuitive. (Loemker 1969: 292)

Here Leibniz goes against Descartes, who emphasized the intuition of clear and distinct ideas at every step in thought and held that thinking of a certain complex concept presupposes permanent intuitive awareness of the concepts that compose it.

If intuition is 'the mind's eye' we understand Leibniz' choice of the expression 'blind thought' for symbolic thought in which intuition is not involved. Symbolic thought occurs, as Leibniz says, 'almost everywhere' but the paradigm cases are the calculi of arithmetic and algebra, such as operating in the decimal place-value system for numbers. This wide use of symbolic thought is similar to Wittgenstein's wide use of the notion of calculus to bring out features of language, but which nevertheless has the calculi of arithmetic and algebra as paradigm cases. A crucial thing about a calculus, and therefore of symbolic thought, is that its structural features, the forms of its signs and expressions, are tied to the expressions as objects of visual perception, and not to a verbal reading of the expressions as in the rhetorical practices of Ancient mathematics.

One might think that Leibniz notion of intuition and intuitive thought corresponds to the content that comes to expression in what Wittgenstein calls prose, or mathematical prose. But that is not the case. There is, as far as I can see, no counterpart in Wittgenstein thinking to Leibniz's 'intuition'. It is a notion that seems to have its source in Leibniz's metaphysical idealism. But as Esquisabel has pointed out, Leibniz suggests two different kinds of blind thought (Esquisabel 2012). In addition to the blind thought that takes the operational practices of arithmetic and algebra as paradigm cases and which Esquisabel calls symbolic blind thought, 
Leibniz recognizes certain contexts in which the signs are words or sentences of ordinary language and where there is non-intuitive thinking that involves a certain comprehension of linguistic meanings of words and sentences, although it is often confused, vague or even erratic. Esquisabel calls this kind of blind thought verbal blind thought and he recognizes its occurrence as follows:

This is the case fundamentally when we appeal to ordinary language in everyday life in our social interchanges or in our meditation. In such situations we face another form of blind thought that is characterized by the fact that we have a vague and confused comprehension of the meanings of words or sentences, with no possibility of better specifying that meaning. Thus, our mind moves so to say in a milieu of diffused linguistic comprehension in which meaning cannot be established univocally and firmly. (Esquisabel 2012: 16)

Leibniz mentions this verbal blind thought in connection with problems arising in the interpretation of biblical texts when questions about the truth of faith arise, questions that may be subjected to a variety of interpretations that can be mutually incompatible. Meanings in verbal blind thought are loaded with a high degree of confusion and uncertainty, and for this reason according to Leibniz - it involves a severe danger for philosophical thinking, namely the threat of talking equivocally and metaphorically about things, about which we have no genuine understanding.

Wittgenstein recognized much the same dangers in the use of prose, in particular in mathematical prose, so it seems to me that the distinction between symbolic blind thought and verbal blind thought in Leibniz's philosophy, is a clear forerunner of the middle period Wittgenstein's distinction between calculus and prose.

Let us take a look at important features of the algebraic symbolism, in order to get closer to the roots of the calculus/prose distinction. As Krämer points out, through the algebraic symbolism of Vieta, a new kind of writing was introduced, a kind of writing that speaks to the eyes and not to the ears (Krämer 1996: 84). The essential feature of the algebraic signs is their visual, graphical form. This form is not given through verbal descriptions, definitions or 
'rules of formation'; the form of a sign is basically given by being shown or presented.

For alphabetical writing, on the contrary, there is a transition to spoken language. Alphabetic writing is a sort of representation in visual space of temporal sequences of spoken language. Every letter has a characteristic sound. Learning to read alphabetic text involves learning not just what the letters look like but also how they sound. Every word has a pronunciation and each sentence has a reading. Understanding alphabetic writing, you have to be able to read the written text aloud, and hear what is expressed in it.

The letters A, B, C,... are used by Vieta in his algebraic symbolism as variables or parameters, but the characteristic sounds of these letters are completely irrelevant in the algebraic symbolism of his analytical art.

But even algebraic signs have verbal readings or readings in mathematical prose, these readings are, however, in general irrelevant and often incomprehensible if they are not given together with the algebraic sign and a stipulation of the form: "An expression of this form is what we will call so and so". It is the visual form of the algebraic signs that give sense through stipulation to these verbal readings, and not the other way around. Consider for instance the sign

$$
a^{2}
$$

with the verbal reading "a raised to 2". There is nothing in this verbal phrase, taken by itself that tells us that this sign must look exactly like this: $a^{2}$. So the meaning of the phrase "a raised to 2 " is determined by the stipulation that this graphical form is what we shall call "a raised to 2". The point of having the verbal readings of algebraic signs is that it facilitates communication. A teacher who is demonstrating how solve a quadratic equation on the blackboard for his students, will use this verbal reading of the algebraic symbols in addressing the students. But if this teacher had solved the same equation for himself on paper, he would not have said a word but just calculated.

So let me summarize: Algebraic writing is not based upon a transition from written to spoken language or conversely (as in the 
case of alphabetic writing). It speaks directly to the eye. The algebraic sign is a visual, graphical structure that is immediately accessible to the human eye. The form of a sign is given by it being shown or presented.

Signs in this sense was, it seems to me, what Leibniz meant by characters. Leibniz talks about the signs of his calculi as characters. He says, for instance:

The human mind cannot advance far in reasoning without resorting to characters. And characters, when they are adequately chosen, have this marvellous property: they leave so to say visible marks of our thoughts on paper, and [thus] we provide ourselves with the means of being infallible. (Quoted in Esquisabel 2012: 23)

Another notion is that of an algebraic symbol (which must not be confused with an algebraic sign). The important thing here is that the algebraic symbolism is an operative symbolism. A symbol is determined by how we operate with the sign for it. Or, as Wittgenstein expresses his concept of a symbol in the Tractatus:

In order to recognize the symbol in the sign we must consider the significant use. (TLP 3.326)

Consider for instance the rule

$$
a^{2}=a \times a
$$

which is one of the rules that determines the sign ' $\mathrm{a}^{2}$ ' as a symbol. By this rule it is connected to the rules for multiplication.

When the rules for operating with the signs in a symbolism are stated only in terms of signs as visual structures (characters) without any use of prose, then we have what Leibniz called a calculus. Leibniz says:

Calculus is $[\ldots]$ operation by means of characters, which takes place not only in quantity, but also in all other reasoning. (Quoted in Esquisabel 2012: 23)

Typical examples of calculi in this sense, according to Leibniz, are operating with ciphers in the algorithms for addition, multiplication, subtraction, division in the decimal place-value system. 
Leibniz had the idea of a comprehensive system, a Universal Characteristic in which verbal language has been made superfluous. In that system truth has been reduced to correctness of calculation.

We do not believe in the possibility of such a universal calculus, but not so much because of the incompleteness and undecidability results in modern mathematical logic, but rather because, as times have changed, we can't share Leibniz's optimistic rationalism.

It would be a mistake to speak about the signs of the algebraic and arithmetical symbolisms (including Leibniz's characters) as "syntactical objects" as the word "syntax" has come to be used in the wake of Gödel, Tarski and Carnap, when syntax is contrasted with semantics and a new technical sense of meta-mathematics, formalization, formal system, etc., was introduced. In this conception, which was based on a naturalistic conception of language, syntactical objects are mathematical entities. To transform the signs in the arithmetical symbolism, for instance, into syntactical objects is the first step in the formalization of arithmetic. It is to give a mathematical representation of the signs (that are given as visual structures) using the mathematical concept of a finite sequence in stating "rules of formation" for numerical signs and expressions. It is important to realize that formalization in this sense is applied mathematics. As I have pointed out before, Carnap was well aware of this and he states this naturalistic view of language explicitly in his book The Logical Syntax of Language. Through formalization in this sense, a mathematical structure is built into the syntax of a formal system, and it is this structure that is used in the so-called arithmetization of syntax that was an important method in Gödel's work. Even if a syntactical object is a finite object in the mathematical sense, it may be too complex to be a structure in visual space that can be perceived by the human eye.

Hilbert's notions of formulas, proofs etc. were different. $\mathrm{He}$ states explicitly in explaining his proof theory that "A proof is an array that must be given as such to our perceptual intuition" (Hilbert 1927: 465).

The syntactical objects, in Carnap's sense, are not "prior to mathematical thought" (to use an expression of Hilbert's), they are the result of mathematical construction. 
It is interesting to compare what I have said about algebraic signs as visual structures perceivable by the human eye, with what Hilbert says about what he calls die finite Einstellung. This is what he says in an English translation of the article "Die Grundlagen der Mathematik" from 1927:

as a condition for the use of the logical inferences and the performance of logical operations, something must already be given to us in our faculty of representation [in der Vorstellung], certain extralogical concrete objects that are intuitively [anschaulich] present as immediate experience prior to all thought. If logical inference is to be reliable, it must be possible to survey these objects completely in all their parts, and the fact that they occur, that they differ from one another, and that they follow each other, or are concatenated, is immediately given intuitively [...]. And in mathematics, in particular, what we consider is the concrete signs themselves, whose shape $[\ldots]$ is immediately clear and recognizable. (Hilbert 1927: 464-5; emphasis added)

Hilbert repeats this statement of die finite Einstellung, in many of his papers on the foundations of mathematics from the beginning of the 1920's to the beginning of the 1930's. And he repeats it using almost the same words, which indicates that it was a deep and strong conviction. Hilbert, unlike Carnap, did not have a naturalistic conception of signs, but rather a sort of phenomenological view of signs.

A characteristic feature of Hilbert's philosophical statement of die finite Einstellung, is that he is standing outside mathematics when he states it. He is looking at mathematical sign language from the outside, and he explicitly calls his perspective a philosophical view. He does not use mathematical symbolism or concepts in what he says about signs, for instance.

However, when he passes over to the proof theoretical work, he places himself inside mathematics. But then die finite Einstellung turns into something else than the philosophical perspective it was from the beginning. It turns into a mathematical concept within a classification of methods of proof inside mathematics. He distinguishes between finite and transfinite methods, for instance. Most of the features he ascribes to the "concrete signs that are intuitively present as immediate experience" have somehow 
disappeared, since he is now concerned with mathematical objects and methods. For instance, the 'part-whole structure' of the immediately recognizable objects (signs) of die finite Einstellung is not the same structure as the imposed part-whole structure of the numerical terms and formulas in formalized arithmetic. It is no longer clear how the details in his statement of die finite Einstellung influences the proof-theoretical work. Even Hilbert's distinction between real and ideal mathematical statements seems to be based on a mathematical conception of finitary proof and reasoning. It is not clear how the notion of the 'concretely finite' of die finite Einstellung, (which is bounded by human perceptual capacities), can justify Hilbert's finitary mathematical methods of proof, which according to Hilbert "includes recursion and intuitive induction for finite existing totalities" (Hilbert 1923: 1139). Hilbert points out, for instance, that "The assertion that all the objects of a finite existing surveyable totality possess a particular property is logically equivalent to a conjunction of several individual assertions" (Hilbert 1922: 1122). But what shall we say if such a totality is so large that it is not surveyable, but still finite? Well, then we are no longer talking about the 'concretely finite', but about mathematical finitude.

It seems to me that this kind of gap between the 'concretely finite' of die finite Einstellung and the normal mathematical notion of the finite manifests a serious difficulty in Hilbert's program. The difficulty, it seems to me, is due to Hilbert's underrating of the conceptual importance of the operative symbolism of arithmetic. Note that in his statement of die finite Einstellung he talks about signs but never about the use of signs.

In Hilbert's paper (1922: 1122), he ends the statement of the finite Einstellung by saying: "In the beginning was the sign." And then he goes on to "explain the numbers", by saying: "The sign 1 is a number. A sign that begins with 1 and ends with 1, and such that in between + always follows 1 and 1 always follows + is likewise a number."

What Hilbert should have said is this:

In the beginning was the use of signs. 
A written mark or figure becomes a sign when it has got a use as a sign. If Hilbert had said "In the beginning was the use of signs", he could have continued: The use of signs creates symbols such as the numbers, and the successor operation. The symbol 1 is a number. The symbol ' +1 ' is the successor operation: if $n$ is a number, then $n+1$ is (the next) number in the series of natural numbers.

The German philosopher Alois Müller criticized Hilbert for his talk about signs having no meaning (Müller 1923). As a result of this criticism, Hilbert changed his terminology. He uses the word numeral (Ziffer) or number sign instead of sign. So now the "explanation of numbers" reads: the numeral 1 is a number, and numerals of the form $1+1,1+1+1$, etc. are numbers. This was, it seems to me, an unfortunate decision since we certainly want to distinguish between numerals and numbers, as we must distinguish between signs and symbols. Hilbert's decision manifests ignorance of the operational aspect of the arithmetical symbolism, where numbers and other symbols are constituted.

That Hilbert wanted to limit himself to 'surveyable' totalities in talking about all objects of a totality, is connected with the concrete sense of finitude of die finite Einstellung, which is subject to the human capacity to survey a totality of objects. But as a mathematician, Hilbert (and other proof-theorists) tended to find this restriction 'troublesome'. The mathematics of proof-theory runs smoother without it. As Mancosu has pointed out, there is a clear change of emphasis concerning the sense of the word 'finite' in Hilbert's writings during the 1920's (Mancosu 1998: 168). The mathematical sense of the word becomes more important, even if Hilbert never abandoned the philosophical view of die finite Einstellung. I think that there is a conflict here in Hilbert's thinking that was never resolved. Hilbert wanted the two senses of 'finite' to be to a great extent one and the same, but they are essentially different. One of them has to do with the human capacity to perceive finite structures in visual space, the other is the pure mathematical notion of finitude (of the calculus of finite sets and sequences, for instance). It is even misleading to think of the latter 
notion of finitude as an extension of the former. They are different concepts. $^{35}$

What is the reason for Hilbert's ignorance of the use of signs, of the rules for the use of signs in the operative symbolism in arithmetic? I think it has to do with his vision of the essence of mathematics as captured in formalized mathematics, which is a vision of something static and completed, as for instance when he says "mathematics proper, or mathematics in the strict sense becomes a stock of provable formulae" (Hilbert 1922: 1131). Mathematics is seen as consisting essentially of the proved theorems, something completed, and not of the activities and ongoing operational practices where mathematical problems are solved.

In formalized mathematics the theorems are formulas with readings in mathematical prose and Hilbert seems to have had very great confidence in the understanding that is based on these prosereadings. I see this confidence as a part of his attitude to accept classical mathematics essentially as it stands (except that its consistency has to be established). And his confidence in the (passive) mathematical prose tends to push aside the activity aspect of mathematics, and to block seeing the importance of the operative symbolism.

It is interesting that Leibniz main motivation for his symbolic approach is connected with the limitations of the human mind that we find in Hilbert's finite Einstellung, such as for instance the limited human capacity to survey a totality of objects. Leibniz says,

For example, we often grasp a number, however large, all at once in a kind of blind thought, namely when we read ciphers on paper which not even the age of Methusela would suffice to count explicitly. (Loemker 1969: 76$)^{36}$

I suppose that what Leibniz has in mind here is, for instance, a symbol or number such as

\footnotetext{
${ }^{35}$ For a more detailed discussion of this topic see Stenlund (2012b).

${ }^{36}$ Leibniz is joking here. According to the Hebrew Bible, Methusela is purported to be the oldest person to ever live. Extra-biblical tradition maintains that he died at the age of 969.
} 
In understanding this number (in the decimal place-value system), we have (in general) no intuitive awareness of the individual numbers that we have to go through in counting from 1 up to this number. The thought of the number 1248 is what Leibniz calls a symbolic or blind thought.

In another context Leibniz says:

Thus, nobody could carry out in his mind reasonings that are extremely lengthy, had not certain signs been invented, that is, names by means of which the overwhelming amount of things could be embraced in such an abbreviated way that this multitude can be gone through. Such a thing would be impossible if, by suppressing names or other signs like these, definitions were to be used in place of that defined. And I use to call such thoughts blind. Nothing is more necessary or frequent for man than them. (Esquisabel 2012: 14; translation slightly amended)

Let us consider the following equation:

$$
10^{40} \times 10^{30}=10^{70}
$$

We see immediately that this is a true equation, thanks to the use of the symbol for multiplication and the exponential notation that gives us the symbols $10^{40}, 10^{30}$ and $10^{70}$. We can recognize the truth of the equation on the basis of this symbolism alone, while remaining 'blind' to what logicians call the "canonical form" of this equation, obtained by replacing these symbols, and the multiplication symbol by their definitions until we have an equation between extremely long sequences of the form (using Hilbert's notation):

$$
1+1+1+1+1+\ldots+1 \text {. }
$$

Could this equation be written down in its entirety on paper? After all, Archimedes estimated the number of grains of sand that would fill up the (Classical Greek) Universe, to about $10^{63}$, which is a much smaller number than $10^{70}$. 


\section{Contemporary physics and symbolic mathematics}

I will end this paper by relating questions I have discussed to issues that were absolutely central to much philosophy done in Wittgenstein's time, namely, the difficulties of interpretation that arose with the invention of relativity theory and quantum physics in the 20th century. More precisely, I will look at what two physicists said about the conceptual problems confronting contemporary physics. This will shed further light on how Wittgenstein's philosophy of mathematics was related to issues central to the exact sciences of the day.

The great changes of scientific thinking that came about with the invention of relativity theory and quantum physics led to the "downfall of classical physics and to strange new conceptions of the physical world", as the physicist A.S. Eddington expressed it in his Gifford Lectures in 1927 (Eddington 1931). What is of interest for us about this development is that it also led to a new awareness of the importance of symbolism in science and in particular of the fruitfulness of symbolic mathematics.

Eddington writes:

One of the greatest changes of physics between the nineteenth century and the present day has been the change in our idea of scientific explanation. It was the boast of the Victorian physicist that he would not claim to understand a thing until he could make a model of it; and by a model he meant some

thing constructed of levers, geared wheels, squirts, or other appliances familiar to an engineer. Nature in building the universe was supposed to be dependent on just the same kind of resources as any human mechanic. [...]

Nowadays we do not encourage the engineer to build the world for us out of his material, but we turn to the mathematician to build it out of his material. [...] We are dealing in physics with a symbolic world, and we can scarcely avoid employing the mathematician who is the professional wielder of symbols. (Eddington 1931: 209; emphases added)

A prominent mathematician who made significant contributions to modern physics in this spirit was Hermann Weyl. He was a scientist, a mathematician at heart, but he had extensive philosophical interests, which affected his work as a mathematician 
and his contributions to contemporary theoretical physics. He was a student of Hilbert's, and from about 1912 to the publication of his book Das Kontinuum in 1918, Weyl was influenced by Poincaré and by Husserl. ${ }^{37}$

In 1919 Weyl met L.E.J. Brouwer and was deeply influenced by his philosophical ideas in general and in particular by his mathematical intuitionism with its emphasis on intuitively cognizable truths. Weyl later described himself as having been a disciple of Brouwer by this time. However, in the beginning of the 1920's, Weyl became more and more doubtful about the sufficiency of the intuitionistic as well as the pure phenomenological approach for the understanding of modern science. In 1927 he wrote: "With Brouwer, mathematics gains the highest intuitive clarity; his doctrine is idealism in mathematics thought to the end. But, full of pain, the mathematician sees the greatest part of his towering theories dissolve in fog" Weyl 1927: 136). By this time Weyl had become convinced that contemporary 'creative science' must transcend what is intuitively and phenomenologically given. He seems to have accepted that Brouwer's intuitionism, as well as pure phenomenology, are incapable of accounting for contemporary theoretical physics. In 1932, Weyl wrote:

The scientific formulation of the objective conception of the world takes place in physics, which employs mathematics as a means of construction. But the situation that prevails in theoretical physics in no way corresponds to Brouwer's ideal of a science, to his postulate that every proposition shall have its individual meaning, and that this meaning shall be capable of intuitive display. On the contrary, the propositions and laws of physics taken individually do not have a content which can be verified experimentally; it is only the theoretical system as a whole which can be confronted with experience. What is achieved is not intuitive cognition of an individual or general state of facts, and a description which faithfully portrays the given conditions, but theoretical, purely symbolical construction of the world. (Weyl 2009: 78; emphases added)

37 For an up-to-date survey of Weil's foundational thinking and its relation to phenomenology in the period 1910-1930, see Mancosu and Ryckman 2002. 
It seems to me that much the same criticism applies to Husserl's idea of a science, since Husserl too presupposed that every proposition shall have its individual meaning. Later Weyl sums up the main point by saying,

in the natural sciences we are in contact with a sphere which is impervious to intuitive evidence; here cognition necessarily becomes symbolical construction. Hence we need no longer demand that when mathematics is taken into the process of theoretical construction in physics it should be possible to set apart the mathematical element as a special domain in which all judgments are intuitively certain; from this higher viewpoint which makes the whole of science appear as one unit, I consider Hilbert to be right. (Weyl 2009: 80)

Symbolical construction, in which the symbols, in themselves, do not always signify anything accessible as intuitive experience, is henceforth Weyl's mathematical approach in theoretical physics. The great importance he attached to this new symbolic orientation is clear from the following statement: "[...] only in mathematics and physics, as far as I can see, has symbolic-theoretical construction acquired sufficient solidity to be convincing for everybody whose mind I open to these sciences" (Weyl 2009: 82).

He describes essential features of this constructive symbolic cognition as follows:

Upon that which is given, certain reactions are performed by which the given is in general brought together with other elements capable of being varied arbitrarily. [...] By the introduction of symbols, the judgments are split up; and a part of the manipulation is made independent of the given and its duration by being shifted on to the representing symbols which are time resisting and simultaneously serve the purpose of preservation and communication. Thereby the unrestricted handling of notions arises in counterpoint to their application, ideas in a relatively independent manner confront reality. [...] Symbols are not produced simply "according to demand" wherever they correspond to actual occurrences, but they are embedded into an ordered manifold of possibilities created by free construction and open towards infinity. (Weyl 2009: 118-9) ) $^{38}$

\footnotetext{
${ }^{38}$ What Weyl means by this will hopefully be clearer by the examples I present throughout this section, especially the example with the introduction of an arithmetical symbolism for counting sequences of sounds at the end of this section.
} 
In these, and similar statements of Weyl's, it seems to me that he is on the verge of saying that most (if not all) of the propositions of the theoretical, symbolic systems of quantum physics, are not really propositions about anything external to the system, but rather rules or laws of a calculus whose "manipulation is made independent of the given". When it is said that this system as a whole depicts a "transcendent symbolic world", I think that it must not be taken as an ontological or metaphysical statement, but rather as an epitome of the successful applications of the system as a whole; its function, significance and importance in the practices of modern physics. ${ }^{39}$

Weyl illustrates the mentioned "splitting up of judgments" by using a simple example from the propositional calculus (Weyl 2009: 187). He points out that in formalized mathematics formulas of the form $\mathrm{A} \rightarrow \mathrm{B}$ have replaced the statement that A implies B or that B follows from $A$. The split consists in the fact that after the replacement, the sign ' $\rightarrow$ ' stands for a symbol that is manipulated only according to the formal rules of the system, and not on the basis of the intuitive reading or 'prose-translation' of the symbol as 'implies' or 'follows'. Weyl summarizes his point by saying: “[...] in principle we must sharply distinguish between the symbol $\rightarrow$ occurring within the system, and such words as "follows" which we use to make meaningful communications about the game". (We note in passing that Weyl's "split" has strong similarities with Wittgenstein's "split" between calculus and prose.) Weyl goes on to make the following claim about the importance of this distinction:

[...] a split of essentially the same nature has been brought about by quantum physics: namely the split between the physical phenomenon under observation on the one hand and the measurement on the other. The first can be adequately described only by the quantummechanical symbolism; about the latter we can and must talk in the

\footnotetext{
${ }^{39}$ Scholz $(2006,306)$ says that "Weyl tried, as much as he could, to distance himself from classical metaphysics, in particular its reference to the kind of transcendent reality that was stipulated there. He definitely refused, however, to cut the bonds to all kinds of metaphysics. He rather substituted strong references to symbolical and material practices in place of the old realism." I agree with Scholz, but I would not want to call Weyl's reference to "symbolical and material practices" an expression of a bond to "a kind of metaphysics".
} 
intuitive terms of classical physics. [...] In quantum theory we learn that measuring one quantity sometimes utterly destroys the possibility of measuring another quantity. This is a matter of principle and not of human deficiency.

The principle referred to here is Heisenberg's uncertainty principle, which asserts a fundamental limit to the precision with which certain pairs of physical properties of a particle, such as position and momentum, can be known simultaneously. As a consequence of the uncertainty principle there is an inconsistency of classical logic with the facts of measurement of variables in quantum mechanics, such as the position and momentum of a particle. The classical distributive law of propositional logic

$(\mathrm{A}$ and $(\mathrm{B}$ or $\mathrm{C})) \leftrightarrow((\mathrm{A}$ and $\mathrm{B})$ or $(\mathrm{A}$ and $\mathrm{C}))$

fails. If $\mathrm{p}$ is a particle moving to the right on a line and $\mathrm{A}$ is the proposition that " $\mathrm{p}$ moves to the right" and $\mathrm{B}$ is " $\mathrm{p}$ is in the interval $[-1,1]$ " and $C$ is " $p$ is not in the interval $[-1,1]$ ", then $(B$ or $\mathrm{C})$ is true, and so is $(\mathrm{A}$ and $(\mathrm{B}$ or $\mathrm{C})$ ). But $(\mathrm{A}$ and $\mathrm{B})$ and $(\mathrm{A}$ and $\mathrm{C})$ are both false since they assert tighter restrictions on simultaneous values of position and momentum than is allowed by the uncertainty principle. The 'uncertainty' of the uncertainty principle is not due to inaccuracy of the methods and instruments of measurement; it arises from the wave nature in the quantum mechanical description of nature, which is why it is a matter of principle.

The failure of the distributive law has been taken to mean that a radical revision of classical logic would be necessary in quantum physics. In his early papers on quantum logic, Hilary Putnam exclaimed that "The world has a non-classical logic?" (Putnam 2012: 173)

But doesn't Putnam here presuppose that the 'symbolic world' of quantum physics is a kind of copy or representation of physical reality, rather than a symbol, a complex symbolical construction? It is not clear to me that the symbolic world of Eddington and Weyl has a logical structure that would somehow have an independent existence. If the symbolic world "has a logic", this logic must be a symbolic construction as much as everything else in the symbolic world of quantum physics. 
Let us look at another of Weyl's examples of the limitations of the use of "the intuitive prose of classical physics". He presents an algebraic-arithmetical equation indicating the propagation of a plane monochromatic light wave (Weyl 2009: 107). The equation contains several parameters, such as the wave frequency $v$, the intensity $a^{2}$, time and space coordinates $t, x, y$, $z$, etc. To speak only in the formal language of the algebraic-arithmetical equation, avoiding all terms that refer to ideas of space and sense qualities would be too pedantic according to Weyl. But, nevertheless, he insists that "in principle, one must hold to the position that nothing of the intuitive contents and essence of these terms enters into the systematic symbolical construction of the physical world!"

Weyl raised the question of whether this two-level view of language is only a feature belonging to an early stage of the development of quantum physics, a feature that will be overcome in its future development. But Weyl is inclined to answer this question negatively. He says that in quantum physics,

one has to distinguish sharply between the hidden physical process which can only be represented by the symbolism of quantum physics, although it may be referred to by such words as electron, proton, quantum of action, etc., and the actual observation and measurement. According to Bohr, we have to talk about the latter in the intuitively comprehensible language of classical physics; or ought we better say: in the language of everyday life? [...] It may very well be that we can never dispense with our natural understanding of the world and the language in which it is expressed, perhaps a little purified and enlightened by classical physics, and that the symbolism of quantum physics will never be able to offer a substitute for it. In this case we would have here a true dialectic which cannot be resolved/lifted by any historical development[.] (Weyl 1948: 340-1; quoted in Scholz 2006: 302-3)

As Scholz points out, in Weyl's mature views on this issue a reference to

'concrete activities of people' comes into play and allows us to adopt even an 'antropic' perspective with respect to mathematical knowledge. [...] we find that mathematical symbols are understood within the context of a communicative practice that has strong parallels to material practices, in the way that symbols are handled, and 
with multiple links to the other scientific and technical activities. (Scholz 2006: 305)

Here one comes to think of the 'anthropological' element that enters in Wittgenstein's work on rule-following in the middle of the 30's, as it comes to expression, for instance, in the following remarks from Wittgenstein's Remarks on the Foundations of Mathematics,

Following a rule is a human activity. (331)

The agreement of people in calculation is not an agreement in opinions or convictions. (332)

Language, I should like to say, relates to a way of living. (335)

The words "language", "proposition", "order", "rule", "calculation", "experiment", "following a rule", relate to a technique, a custom. (346)

$[\mathrm{W}]$ hat the correct following of a rule consists in cannot be described more closely than by describing the learning of 'proceeding according to the rule.' And this description is an everyday one, like that of cooking or sewing, for example. It presupposes as much as these. It distinguishes one thing from another, and so it informs a human being who is ignorant of something particular. (392)

I know of no evidence, however, for Weyl's having been influenced by Wittgenstein's work in the 1930's and 40's. Weyl had read the Tractatus. It is listed as one of the references in Weyl's article "Über den Symbolismus der Mathematik und Mathematischen Physik" (1953), and Weyl makes some short comments on a few remarks in the Tractatus. But there is nothing in this article that would show the Tractatus to have been an important influence on Weyl.

The similarities we find in Weyl's and Wittgenstein's early symbolic views of mathematics, are rather due to their common source of inspiration: Heinrich Hertz.

When he raises the question of the origin and nature of the procedure of symbolic construction, Weyl refers to Heinrich Hertz (Weyl 2009, 107-8). He quotes at length the crucial passage from the beginning of the introduction to Hertz' Principles of Mechanics, where Hertz explains that we create symbols of external objects in such a way that "logically necessary consequences of the symbols are always the symbols of caused consequences of the symbolized 
objects". It is a crucial feature of Hertz' symbolic view that the symbols, being our concepts of objects in nature, are not assumed to have anything further in common with the objects except this requirement. As Hertz puts it: "We neither know, nor do we have means to find out whether our representations of the objects have anything in common with the objects themselves except that one fundamental relation alone." As pointed out before, it was this feature of Hertz' work that Ernst Cassirer had in mind when he wrote that "Heinrich Hertz is the first modern scientist to have effected a decisive turn from the copy theory of physical knowledge to a purely symbolic theory" (Cassirer 1957: 20). ${ }^{40}$

It may seem as though symbolic mathematics in Weyl's conception only refers to very advanced mathematics, such as the mathematics used in modern theoretical physics. But the essence of introducing a symbolism, according to Weyl, is a transition from description to construction, by means of the "splitting up of judgments" mentioned before, and such transition occurs already at the most elementary levels of mathematics as in the creation of the sequence of natural numbers 1, 2, 3, .. According to Weyl, we have here a typical example of the construction of a symbolism.

Weyl asks us to imagine hearing two sequences of sounds, one after the other (Weyl 2009: 117). ${ }^{41}$ In reproducing the sounds of the first sequence by recollection when listening to the second we may ascertain that the second sequence projects beyond the first. "This time there were more sounds than the first time." Here we have a description, which can be understood without any reference to symbols. But, we may proceed in a different way. While listening to the sounds we put strokes on paper one after the other, one stroke for each sound. We may thus get the number-symbols | | | | called 4 for the first sequence, and |||||| called 6 for the second one, and now we ascertain from the symbols: $6>4$. In doing this, the two

\footnotetext{
${ }^{40}$ It is sometimes suggested that Weyl's main source of inspiration for his symbolic approach was not so much Hertz but rather Cassirer's "Philosophy of Symbolic Forms". But that is doubtful in view of Weyl's critical remarks about Cassirer's very wide use of the notion of 'symbolic form'. Weyl finds it difficult to read Cassirer's Philosophy of Symbolic Forms as "variations on a single theme" (Weyl 2009: 195).

${ }^{41}$ Weyl uses this example several times in his publications.
} 
sequences of sounds may already have disappeared into silence. So the stroke-symbols are in that sense time-resistant and serve the purpose of preservation and communication, which are crucial features of a symbolic construction. For relatively small number symbols like these we see immediately that $6>4$, but for larger numbers a certain manipulation in the symbolism may be necessary: We cross out the first stroke from each symbol and repeat this operation until one symbol is exhausted.

If the ordinary number-signs $1,2,3, \ldots$ belong to the symbolism, we would also have the rules or conventions:

$$
1=|, 2=||, 3=|||, \ldots
$$

where the equality sign means that one symbol may be replaced by the other. An arbitrary numerical stroke sign |||||| $\mid$, say, is thus of the form:

\section{$((((((\mid) \mid) \mid) \mid) \mid) \mid) \mid)$}

which we may call "the normal form" of this numeral. Here we see that the number signs that are 'smaller than' |||||| $\mid$ are proper parts of this number sign. We take this relationship to define 'smaller than'. Calling this number sign "arbitrary" means here that the process of constructing numeral stroke signs is without end; no limit to the length of a number sign is stipulated. In order to define the general numerical stroke sign, we introduce an arbitrary letter " $n$ ", and define the general numerical stroke sign as the sign complexes obtained from " $n$ " after eliminating " $\mathrm{n}$ " by either replacing "n" by "n |" or replacing "n" by "|". The stroke sign | | $\mid$, for instance, is obtained after four operations, deriving in turn $\mathrm{n}, \mathrm{n}|, \mathrm{n}||, \mathrm{n}|||,|| \mid$; here we have replaced " $\mathrm{n}$ " by " $\mathrm{n} \mid$ " three times in succession, and then replaced " $n$ " by "|". Here the symbol " $\mathrm{n} \mid$ " is the successor-operation, usually written $\mathrm{n}+1$, and the symbol " $\mathrm{n}$ " is the number variable.

Defining the general numerical stroke sign in this way is what Weyl expresses in mathematical prose by saying that we have embedded the "the actually occurring number symbols into the sequence of all possible numbers. This sequence originates by means of a generating process in accordance with the principle that from a given number a new one, the following one, can always be 
generated by adding the unit" (Weyl 2009: 118). And he adds, "Only then does arithmetic proper come into existence with its characteristic principle of the so-called complete induction, the conclusion from $n$ to $n+1$."

Weyl also points out that it is "the determination of numbers which is of an essentially symbolic character. 'There were 4 tones' is unintelligible without reference to a symbol" (Weyl 1949: 36). The determination of the number of objects of a collection, takes place through counting, but as R.L. Goodstein has emphasized, counting is at bottom not a process of discovery, but of transformation (Goodstein 1956: 124). ${ }^{42}$ This is so because the only difference between counting objects of a collection, and transforming a number-sign pattern lies in the initial step of replacing each object by "|", i.e. regarding each object of the collection as a unit, as one. So imagining this replacement as having been carried out for a collection of objects, we are regarding the collection of objects as a number sign. Counting then consists in transforming the collection, regarded as a number sign, into a conventional numeral that presents the numeral in its "normal form".

As mentioned before, there is an ambiguity in the conventional use of the words "sign" and "symbol" (in Weyl's account, for instance). The word "sign" is often used for the symbol expressed by that sign, and conversely the word "symbol" is sometimes used for the sign expressing a symbol, and the context is taken to be sufficient to indicate what is meant. There is of course an important difference between "sign" and "symbol", as between a numeral (or number sign) on one hand and a number on the other. The number 2 is the role or function of the number sign 2 in the arithmetical symbolism. The numbers sign 2 and the Roman number sign II are different signs, but they express the same symbol, the same number when they are used, for instance, as page numbers in books.

\footnotetext{
${ }^{42}$ This article by Goodstein deserves more attention by philosophers of mathematics. It would have deserved the title "The Origin and Foundation of Modern Arithmetic".
} 
One important thing to understand about this arithmetical example is how the construction of a symbolism is not just the introduction of a notation; it is also the introduction of an operative symbolism, i.e. rules for operating with signs. And, of course, it is not the introduction of signs as 'syntactical objects' (in the sense of Carnap and Tarski) to denote abstract or ideal objects having an independent existence in an ontological or mental realm. Weyl expresses the non-ontological nature of his symbolic conception of arithmetic as follows:

If one wants to speak, all the same, of numbers as concepts or ideal objects, one must at any rate refrain from giving them independent existence; their being exhausts itself in the functional role which they play and their relations of more or less. (They certainly are not concepts in the sense of Aristotle's theory of abstraction.) (Weyl 1949: 36)

The concept of truth will not be of any special importance in Weyl's symbolic arithmetic, any more than in symbolic mathematics in general. The reason is of course that the propositions of symbolic mathematics are not about some independently existing objects or states of affairs.

\section{References}

Aristotle, 1984, The Complete Works of Aristotle, Vols. 1 and 2. Ed. Jonathan Barnes. Princeton: Princeton University Press.

Bell, E.T., 1937. Men of Mathematics. London: Victor Gollancz LTD.

Bottazzini, U., 2003. “Complex Function Theory, 1780-1900”. In Jahnke, ed. 2003, pp. 213-259.

Boyer, C.B., 1968. A History of Mathematics. New York: Wiley, cop.

Brauer, R. and Weyl, H., 1935. "Spinors in n Dimensions". American Journal of Math. 57, pp. 425-449.

Bussey, W. H. 1917. "The Origin of Mathematical Induction”. American Mathematical Monthly 24, pp. 199-207.

Calinger, R., 1999. A Contextual History of Mathematics to Euler. Upper Saddle River: Prentice Hall, cop.

Carnap, R., 1959. The Logical syntax of Language. English ed. first published in 1937, transl. by A. Smeaton. London: Routledge \& Kegan Paul. 
Cauchy, A. 1882-1919. Oeuvres complètes d'Augustin Cauchy. Paris: GauthierVillars.

Cassirer, E. 1957. The Philosophy of Symbolic Forms, Vol. 3: The Phenomenology of Knowledge. New Haven and London: Yale University Press.

Cajori, F. 1918. "Origin of the Name Mathematical Induction". American Mathematical Monthly 25, pp. 197-201.

Corry, L., 2006. “Axiomatics, Empiricism, and Anschauung in Hilbert's Conception of Geometry: Between Arithmetic and General Relativity". In Ferreirós and Gray (2006), pp. 133-156.

De Morgan, A., 1849. Trigonometry and Double Algebra. London: Taylor, Walton, \& Maberly.

Diamond, C. (ed.), 1976. Wittgenstein's Lectures on the Foundations of Mathematics, Cambridge 1939. Chicago and London: The University of Chicago Press.

Eddington, A.S. 1931. The Nature of the Physical World. Cambridge: Cambridge University Press.

Engberg-Pedersen, T., 1979. "More on Aristotelian Epagoge", Phronesis, Vol. 24 (3), pp. 301-319.

Epple, M., 2003. "The End of the Science of Quantity: Foundations of Analysis 1860-1910". In Jahnke (ed.) 2003, pp. 291-323.

Ernst, P., 1982. "Mathematical Induction. A recurring theme." Mathematical Gazzette Vol. 66 (436), 120-125.

Esquisabel, O.M., 2012. "Representing and Abstracting. An Analysis of Leibniz's Concept of Symbolic Mathematics". In Casanave (ed.) 2012, pp. 1-49.

Euclid. Elementa. Post I. L. Heiberg edit E. S. Stamatis. 5 vol. LeipzigStuttgart: B. G.Teubner, 1969-1977.

Ferreiros, J. \& Gray, J.J., 2006. The Architecture of Modern Mathematics. Oxford: Oxford University Press.

Fowler, D., 1994. "Could the Greeks Have Used Mathematical Induction? Did They Use It?” Physis XXXI, pp. 253-265.

Frege, G., 1960. Translations from the Philosophical Writings of Gottlob Frege, Geach, P. and Black, M. (eds.). Oxford: Basil Blackwell.

Frege, G., 1979. Posthumous Writings, H. Hermes (ed.), transl. by P. Long. Oxford: Basil Blackwell.

Frege, G., 1980. Philosophical and Mathematical Correspondence, G. Gabriel, et al. (eds.). Oxford: Blackwell publishers.

Freudenthal, H. 1953. "Zur Geschichte der vollständigen Induktion". Archives Internationales d'Histoire des Sciences 6, pp. 17-37.

Freudenthal, H. 1962. "The main trends in the foundations of geometry in the 19th century". In Ernst Nagel et al., (eds.) Logic, methodology and philosophy of science. Stanford: Stanford Univ. Press, pp. 613-621. 
Goodstein, R.L., 1956. "The Arabic Numerals, Numbers and the definition of Counting", The Mathematical Garette 40 (332), pp. 114-129.

Grassmann, H., 1844. Die Lineale Ausdehnungslehre, ein neuer Zweig der Mathematik dargestellt. Leibzig Otto Wiegand. <https:/ / archive.org/details/dielinealeausde00grasgoog> (Accessed July 17, 2015).

Grattan-Guinness, I., 2004, "The mathematics of the past: distinguishing its history from our heritage". Historia Mathematica, vol. 31, pp. 163-185.

Guicciardini, N., 2003. "Conceptualism and contextualism in the recent historiography of Newton's Principia" Historia Mathematica 30 (4), pp. 407-431. http://dx.doi.org/10.1016/S0315-0860(03)00051-X

Hertz, H., 1956. The Principles of Mechanics Presented in a New Form. New York, Dover (English translation of Die Prinzipen der Mechanik in neuem Zusammanhange dargestellt, Leipzig, 1894.)

Hestenes, D. and Sobczyk, G., 1984. Clifford Algebra to Geometric Calculus. A Unified Language for Mathematics and Physics. Dordrecht: D. Reidel Publishing Company.

Hilbert, D., 1903. Grundlagen der Geometrie, Leibzig: B. G. Taubner. <https://archive.org/details/grunddergeovon00hilbrich> (Accessed July 17, 2015).

Hilbert, D., 1922. “The New Grounding of Mathematics. First Report." In Ewald, W., 1996, From Kant to Hilbert. A Source Book in the Foundations of Mathematics, Volume II. Oxford: Oxford University Press, pp. 11151134.

Hilbert, D., 1923. "The Logical Foundations of Mathematics". In Ewald, W., 1996. From Kant to Hilbert. A Source Book in the Foundations of Mathematics, Volume II. Oxford: Oxford University Press, 1996. Pp. 1134-1148.

Hilbert, D., 1926. "On the infinite” XXX

Hilbert, D., 1927. "The Foundations of Mathematics”. In van Heijenoort, 1967, From Frege to Gödel. Cambridge (Mass.): Harvard University Press, pp. 464-479.

Hopkins, B.C., 2011. The Origin of the Logic of Symbolic Mathematics: Edmund Husserl and Jacob Klein. Bloomington, Indiana: Indiana University Press.

Ishiguro, H. 1990. Leibniz's Philosophy of Logic and Language. Cambridge, New York: Cambridge University Press.

Jahnke, H.N. (ed.), 2003. A History of Analysis. History of Mathematics Volume 24. Providence Rhode Island: Amer. Mathematical Society, London Math. Society.

Jahnke, H. N., 2003. "Algebraic Analysis in the 18th Century". In Jahnke (ed.) 2003, pp. 105-136.

Kastanis, N. \& Thomaidis, Y.: 1991, 'The Term "Geometrical Algebra”, Target of a Contemporary Epistemological Debate', in N. Kastanis 
(ed.), On the Historiography of Ancient Greek Mathematics (pp. 1-26), Group for the history of mathematics of Greek society for the history of science and technology.

$<$ bttp:// users.auth.gr/ nioka/Files/GEOMALGE.pdf> (Accessed July 6, 2015).

Klein, J., 1968. Greek Mathematical Thought and the Origin of Algebra. Cambridge (Mass.), MIT Press.

Kreisel, G., 1958. "Hilbert's Programme”, Dialectica 12 (3-4), pp. 346-372. Krämer, S., 1996. "Mind, Symbolism, Formalism: Is Leibniz a Precursor of Artificial Intelligence?". Knowl. Org. 23 (2), pp.83-87.

Leibniz, G. W. 1962. Matematische Schriften, Hildesheim: Olm.

Loemker, L. E. (ed.), 1969. Leibniz: Philosophical Papers and Letters.

Dordrecht/Boston/London, D. Reidel Publishing Company.

Lützen, J., 2003. "The Foundation of Analysis in the $19^{\text {th }}$ Century". In Jahnke 2003, pp. 155-195.

Mancosu, P. 1998. From Brouner to Hilbert. The Debate on the Foundations of Mathematics in the 1920s. Oxford and New York: Oxford University Press.

Mancosu, P. 1996. Philosophy of Mathematics and Mathematical Practice in the Seventeenth Century. New York: Oxford University Press.

Mancosu, P. \& Ryckman, T., 2002. "Mathematics and Phenomenology. The correspondence between Oskar Becker and Hermann Weyl," Philosophia Mathematica 10, pp. 130-202.

Müller, A. (1923). “Über Zahlen als Zeichen”. Mathematische Annalen 90, pp. 150-159.

Mueller, I., 1981. Philosophy of Mathematics and Deductive Structure in Euclid's Elements. Cambridge (Mass.), MIT Press.

Netz, R. 2004. The Transformation of Mathematics in the Early Mediterranean World. Cambridge: Cambridge UP.

Ortega y Gasset, J. 1971. The Idea of Principle in Leibnitz and the Evolution of Deductive Theory. New York: W.W. Norton \& Company, Inc. (Transl. Mildred Adams.)

Putnam, H., 2012. Philosophy in an Age of Science, Cambridge MA: Harvard University Press.

Rabinovitch, N. L., 1970. "Rabbi Levi Ben Gerson and the Origins of Mathematical Induction". Archive for History of Exact Sciences 6, pp. 237248.

Scholz, E. 2006. "Practice-related symbolic realism in H. Weyl's mature view of mathematical knowledge". In: Ferreirós and Gray 2006, pp. 291309.

Stenlund, S., 2012. "The "middle Wittgenstein" and Modern Mathematics". In: Dybjer et al. (eds.) Epistemology versus Ontology, Essays on the Philosophy 
and Foundations of Mathematics in Honour of Per Martin-Löf. Dordrecht: Springer Science + Business Media, pp.139-159.

Stenlund, S., 2012b. "Different senses of finitude: An inquiry into Hilbert's finitism". Synthese 185, pp. 335-363.

Stenlund, S., 2014. The Origin of Symbolic Mathematics and the End of the Science of Quantity, Uppsala Department of Philosophy 2014:

$<$ <ttp:/ / urn.kb.se/ resolve?urn =urn\%3 Anbn\%3 Ase\%3 Aun\%3 Adiva$221570>$

Thomae, J., 1898. Elementare Theorie der analytischen Functionen einer complexen Veränderlichen, 2nd Ed. Halle a.S.: Nebert.

Unguru, S., 1975. "On the need to rewrite the history of Greek mathematics", Archive for History of Exact Sciences 15, pp. 67-114.

Unguru, S., 1991. "Greek Mathematics and Mathematical Induction", Physis 28, pp. 273-289.

Unguru, S., 1994. "Fowling after Induction, Reply to D. Fowler's comments", Physis 31, pp. 267-272.

Vieta, F. (Viète, François), 1968. Introduction to the Analytic Art, English translation in appendix to Klein 1968.

Van der Waerden, B.L., 1975. "Defence of a 'Shocking' point of view," Archive for History of Exact Sciences 15, pp. 199-210.

Van der Waerden, B.L., 1985. A History of Algebra. From Al-Khwarizmi to Emmy Noether. Berlin: Springer-Verlag.

Weir, Alan, 2011. "Formalism in the Philosophy of Mathematics". In: Edward N. Zalta (ed.), The Stanford Encyclopedia of Philosophy (Fall 2011 Ed.), < bttp:/ / plato.stanford.edu/archives/fall2011/ entries/formalismmathematics $/>$.

Weyl, H., 1918. Das Kontinuum. Veit \& Co., Leipzig, Reprinted 1987. 2 edn, de Gryter \& Co., Berlin, 1932. English translation: The Continuum: $A$ Critical Examination of the Foundation of Analysis, translated by Stephen Pollard and Thomas Bole, Thomas Jefferson University Press: 1987. (Re-publication, Dover 1994.)

Weyl, H., 1927. "The Current Epistemological Situation in Mathematics". In: Mancosu 1998: 123-142.

Weyl, H., 1949. Philosophy of Mathematics and Natural Science (Revised and Augmented English Edition). Princeton: Princeton Univ. Press.

Weyl, H., 1949. "Wissenschaft als symbolische Konstruktion des Menschen". In: Weyl, H. 1968, Gesammelte Abhandlungen, Band IV. Berlin: SpringerVerlag, pp. 289-345. (First published in Eranos-Jahrbuch 1948, pp. 375-431 (1949).)

Weyl, H., 1953." Über den Symbolismus der Mathematik und mathematischen Physik". Studium Generale 6, pp. 219-228. 
Weyl, H., 2009. Mind and Nature: Selected Writings on Philosophy, Mathematics, and Physics, Edited with an introduction by Peter Pesic. Princeton and Oxford: Princeton Univ. Press.

Wittgenstein, L., 1969 [TLP]. Tractatus Logico-Philosophicus, trans. D.F. Pears and B.F. McGuinnes. London: Routledge \& Kegan Paul.

Wittgenstein, L., 1975 [PR]. Philosophical Remarks, $2^{\text {nd }}$ ed., R. Rhees (ed.), trans. R. Hargreaves and R. White. Oxfod: Blackwell, Oxford.

Wittgenstein, L., 1974 [PG]. Philosophical grammar, R. Rhees (ed.), trans. A.J.P. Kenny. Oxford: Blackwell.

Wittgenstein, L., [RFM] 1978. Remarks on the Foundations of Mathematics, $3^{\text {rd }}$ ed., G.H. von Wright, R. Rhees and G.E.M. Anscombe (eds.), trans.

G.E.M. Anscombe. Oxford: Blackwell.

Wittgenstein, L., [NB], 1998. Notebooks 1914-1916, $2^{\text {nd }}$ ed., G.H. von Wright et al. (Eds.). Oxford: Basil Blackwell.

Wittgenstein, L., [BT] 2012. The Big Typescript: TS 213, German English Scholar's Edition, Trans. C. Grant Luchart and M.E. Aue. Oxford: Wiley-Blackwell.

\section{Biographical Note}

Sören Stenlund was appointed professor of theoretical philosophy at Uppsala University (Sweden) in 2000. He has acted as head of the Philosophy Department in Uppsala and was the Director of Graduate Studies in the Department of Philosophy and the coordinator of the seminar for theoretical philosophy until his retirement in 2008. Since his dissertation in 1972, Stenlund has published books and articles on various themes in the philosophies of language, logic and mathematics, such as Language and Philosophical Problems (Routledge 1991). Apart from these themes, Stenlund has discussed a vast array of other philosophical issues concerning the nature and history of philosophy and the philosophy of culture. 